\title{
TOURISM AND DIVERSITY
}

\author{
Zsuzsanna BACSI ${ }^{\mathrm{a}}$ \\ ${ }^{a}$ University of Pannonia Georgikon Faculty, Keszthely, Hungary. 16 Deák F. Str, Keszthely, 8360- \\ Hungary. Phone: +36-83-545366, email: h5519bac@ella.hu
}

Cite this article: Bacsi, Z. (2017). Tourism and diversity. Deturope, 9, 2: 25-57

\begin{abstract}
Cultural attractions are often linked to unique features of the host population, and are often related to a national minority or a segment of the population that preserved their traditions. Ethnically or religiously varied countries may often have such unique attractions, that seem exotic and appealing to tourists. Multiculturality is often an attraction for tourism, offering generally an authentic experience for visitors of different backgrounds. Besides, an ethnically or linguistically varied population can also provide a linguisticaly more skilful labour force, that is more sensitive to the needs of visitors coming from different cultures, and thus create a more comfortable environment for them.

The issue of multicultural societies has recently become a sensitive issue, due to global mass migration. There is a belief that ethnic or cultural fractionalisation would necessarily bring about difficulties of understanding and cooperation, leading to lower economic performance, less stable economic and social processes and, ultimately a slowdown of economic output. The resulting conflicts, difficulties may frighten away tourists and lead to the vulnerability of the tourism sector in very heterogeneous countries. On the other hand, ethnic fractionalisation and the resulting cultural diversity can be welcome as valuable resources as the varied pool of knowledge, traditions, skills, customs, that can enhance innovative ideas and creativity.

In the present paper evidence is looked for the relationship between ethnic, linguistic and religious diversity and tourism performance in a cross-country statistical analysis of 155 countries of the world. Statistical analysis of 155 countries show, that although there is a tendency of lower tourism performance with greated fractionalisation of the society, the most popular and successful tourism destinations are often multicultural and multiethnic societies.
\end{abstract}

Keywords: ethnic diversity, cultural diversity, religious diversity, language diversity, tourism arrivals, tourism receipts, TTCI

\section{INTRODUCTION - PROBLEM OUTLINE}

Tourism attractions are various, including visiting friends and relatives, health, leisure and entertainment, love of nature, and culture. Cultural tourism, as a major tourism motivation, includes visits to tangible and intangible cultural resources, with the intention to gather new information and experiences to satisfy the visitors' cultural needs. These cultural needs can include the solidification of one's own cultural identity, by observing the exotic "other". Cultural traditions are often linked to unique features of the host population, and are often related to a national minority or a segment of the population who preserve their traditions. Ethnically varied countries may often have such unique attractions, e.g. the folklores of native Indians in the US or in South America, aborigines in Australia, the Schvabish minority in 
Hungary, the gipsies in many European countries, the Chinatowns in European and American metropolises. The ethnic folklore includes crafts, celebrations, costumes, food, and many other items that seem exotic and appealing to tourists.

Another such speciality may be the various religious traditions - e.g. the Jewish festivals, music, art, food, Muslim buildings and crafts objects, as carpets, textiles, calligraphy, silvers.

Language can be another aspect of cultural attraction. The French speaking communities in Canada attract visitors from France, and also provide an opportunity for non-French visitors to learn French during their holidays. The German speaking minorities in Europe or in LatinAmerica can contribute to tourism by providing easily accessible language linkages to tourists coming from the German speaking parts of the world. The same is true for Spanish, Arabic, Chinese, and several other languages.

Multiculturality is often an attraction for tourism, offering generally an authentic experience for visitors of different backgrounds. Besides, an ethnically or linguistically varied population can also provide a linguisticaly more skilful labour force, that is more sensitive to the needs of visitors coming from different cultures, and create a more comfortable environment for them.

The issue of multicultural societies has recently become a sensitive issue. Global mass migration to the more affluent countries of the world poses the problem of ethnically increasingly different populations in these countries. The resulting ethnic diversity may go together with cultural fractionalisation, if the new, ethnically different immigrant population will not, or cannot become integrated, keeping strictly to their traditional home culture, customs and marrying within their own subgroup. In this case ethnic differences may survive long after the arrival of the immigrants in the host country, and cultural diversification is maintained in every level of life.

There is a belief that ethnic or cultural fractionalisation would necessarily bring about difficulties of understanding and cooperation, lower economic performance, less stable economic and social processes and, ultimately a slowdown of economic output. The resulting conflicts, difficulties may frighten away tourists and lead to lower performance of the tourism sector in very heterogeneous countries. On the other hand, ethnic fractionalisation and the resulting cultural diversity can be welcome as a pool of valuable resources comprising knowledge, traditions, skills, customs, that can initiate innovative ideas and creativity.

In the present paper evidence is looked for the relationship between ethnic, linguistic and religious diversity and tourism performance in a cross-country statistical analysis of 155 countries of the world. The main objective is to find patterns of diversity that distinguish 
countries that are successful actors in the international tourism scene from those, who are less prosperous in this respect.

\section{LITERATURE REVIEW}

\section{Diversity and economic performance}

Human resources play a crucial part in the performance of the services sectors, including tourism. The quality of human resources is a key component service quality. Educational attainment, innovative capacity, talent, creativity all contribute to better services and higher economic performance. Generally, people in richer countries have better access to educational resource, and are more educated on average (UNDP, 2010).

Access to education is a major factor in development, but there are several limitations that influence the way how people can access activities, services and functions that are important for them. A person may not be able to attend education - even if she or he had the necessary income to pay for it - in case of racial, religious or gender discrimination. Ethnic and religious tolerance are important social values and are often related to the preservation of cultural heritage (Gébert, Bajmóczy \& Málovics, 2017).

The structure of the society, including any types of inequalities - gender, race, religion, social situation - is a determining factor in developing the quality of human resources, and therefore in contributing to the output and income of firms, or of national economies (Barnett \& Kincaid, 1983; Burger-Menzel \& Syring, 2013; Adler \& Gundersen, 2008; Vollmer \& Wolf, 2015; Florida, 2005). However, creativity, talent, and innovation often come from heterogeneous, diverse soceties. In culturally mixed groups of the population the level of creativity may be higher due to the different backgrounds, experiences, attitudes and behavioural traditions, and creativity is a key resource of contemporary economies (Yencken, 1988; Landry, 2000; Florida, 2005; Ságvári \& Dessewffy, 2006). Therefore, a multicultural society, if well managed, can be a valuable asset, but if people of different backgrounds are unwilling or unable to communicate, the result may be lack of cooperation and slow growth.

The effects of ethnic fragmentation across countries was studied by Easterly and Levine (1997) who stated that, ceteris paribus, more ethnically fragmented countries grow less, as is revealed by the poor economic performance of Africa. Similarly, Collier and Gunning (1999) also emphasised the role of ethno-linguistic fractionalization in the lack of social capital, productive public goods, and other growth enhancing policies in Africa.

Fractionalisation has negative effects on growth and productivity mainly in nondemocratic regimes (Collier, 2000), ethnic fragmentation is negatively correlated with the quality of 
infrastructure, literacy, and school attainment, and they are positively correlated with infant mortality (La Porta, Lopez-de-Silanes, Shleifer, \& Vishny, 1999; Alesina et al., 2003). Alesina and LaFerrara (2005), in analysing nearly 100 countries for ethnic and linguistic fragmentation, found that fragmentation may have a positive effect on the growth of per capita incomes in developed and wealthy societies, but generally, increasing fragmentation correlates with lower growth of GDP/capita.

Although most of the relevant literature agrees on the negative effects of ethnic fractionalisation on various aspects of development, there are some opposite opinions and results, as is shown in studies about the USA states and cities (Sparber, 2007; Putnam,2007), supporting the view that ethnic diversity, on balance, is an important social asset.

VanAlstine, Cox and Roden (2013) analysed the relationship of linguistic, ethnic and religious fragmentation to the Human Development Index (HDI) for 2003, with indicators of economic freedom, income inequalities, and population and area of the analysed countries as control variables. Their findings showed no significant relationship between the level of development and ethno-linguistic fragmentation, but a significant negative impact of religious fragmentation was established. However, when countries were segmented according to their level of development, a significant positive impact of religious fragmentation was found in the highest income quartile. Alesina- Harnoss and Rapoport (2016a) established a negative impact of ethnic fractionalisation on development, by assessing the relationship between the proportion of foreign-born population and the per capita GDP, segmenting the population by the level of education, and using population and index of democracy as control variables. Alesina, Michalopoulos and Papaioannou (2016b) found that the per capita real GDP depends most on ethnic fractionalisation when income inequalities are high, while the impact of the historical past (type of colonisation, or state foundation, etc.) was not significant on income levels.

Diversity is not always detrimental for development, and ethnic homogeneity is not a requirement for high incomes and development indicators, and the best condition for development is often a medium-level level diversity (Bacsi, 2017a). In a cross-country study of 155 countries a statistically valid negative relationship was established between high ethnic diversity and development, measured either by HDI or by per capita GNI for 2014 and 2015, but no such relationship was found for countries with lower values of ethnic fractionalisation, i.e. for two thirds of the countries analysed. Therefore multiethnicity and variety can often be a beneficial factor for development, on the global level. A more detailed analysis about the joint relationship between cultural, ethnic, linguistic and religious diversity and the level of development provided quantitative evidence for the fact, that while linguistic, ethnic and 
cultural fragmentation has a slight negative effect on the level of development, religious fragmentation may be beneficial to GNI or HDI (Bacsi, 2017b).

\section{Measuring Diversity}

Diversity can be measured in many ways, but one of the most popular formulas is the adaptation of the population diversity index (see Steele, 2008 for details), applied by Greenberg (1956) to measure linguistic fractionalisation. Assuming, that there are $\mathrm{n}$ segments of the population, the formula for the Diversity Index is DI $=1-\Sigma \mathrm{s}_{\mathrm{i}}{ }^{2}(\mathrm{i}=1 . . \mathrm{n})$, where $\mathrm{si}$ is the proportion of the population belonging to group $i$ of the society. Thus the index measures the probability of two randomly selected individuals belonging to different groups. If there is only one such group (i.e. all the population belongs to the same ethno-linguistic group - total homogeneity) the index has the value of 0 , while if each individual belongs to a different group, then the index is equal to 1 . The formula is often used for measuring ethnic, linguistic and religious fractionalisation, too.

It is not easy to determine the exact proportions of the various groups in a society. One of the most widely used database is by Alesina and LaFerrara (2005), containing ethnic and linguistic information collected from the 2001 edition of the Encyclopedia Britannica, and the CIA World Factbook. In their study the ethnic and linguistic fractionalisation indices were compared to GDP per capita (on purchasing parity base) data published by the World Bankfor the years 1960-2000. A weak negative correlation was found between the annual growth rate of GDP per capita and the measure of fractionalisation. Similar results were found by Fearon (2003), who assessed the ethnic and cultural diversities for 160 countries of the world, applying ethnic and linguistic differences and similarities as the basis of cultural diversity.

A linguistic fractionalisation index is regularly published for most countries of the world by Ethnologue (2016), using the Greenberg- formula. Several studies analysed the relationship between linguistic diversity and development, and usually a negative relationship has been found. As Nisnevich (2013) demonstrated, there is a weak negative correlation ( $\rho=$ 0.247) between the annual growth of per capita GDP and the value of the language diversity index, but while there are many countries both very poor and highly linguistically diverse, 7 of the 9 wealhiest countries all have medium to high LDI values suggesting that some level of linguistic diversity is economically useful. Harmon-Loh (2010) gives a detailed overview of the trends of language diversity worldwide, presenting continent-wide series and patterns, and discussion on many methodological questions. 


\section{Sociocultural diversity and tourism: benefits or hindrances}

Culture, together with tourism, is a growing sector of the economy. International tourism enhances understanding between nations and peoples, or can generate conflicts due to cultural misunderstandings.

Cultural and ethnic tourism have been showing an increasing trend in world tourism. The main attractions of cultural tourism are built and physical objects (buildings, objects of arts), values revealed in everyday lifestyle (customs, food, drinks, celebrations), and events and festivals. Heritage tourism builds on historical, archeological, architectural and religious sites, including rural architecture, battlefields, historic graveyards, etc. Ethnic tourism has two main directions: one is motivated by the feeling of homesickness and nostalgia towards one's place of birth, the desire to find one's own roots. The other is to explore and understand a strange, special, exotic culture, either in distant lands or within one's own country, visiting a community of an ethnic minority, and experiencing an authentic culture (Csapó \& Matesz, 2007).

Culture can be a tourist attraction in its many forms including high culture, popular culture and, increasingly, ethnic culture, as is seen in the examples of Chinatowns, Little Tokyos, Thai Towns throughout the world (Lin, 2008).

The cultural activities are increasingly concentrating in ethnically diverse neighbourhoods. As the case of Harlem, USA shows, tourism-based development can be a positive driver for economically backward communities. Harlem, as a tourist destination started to emerge in the 1980s based on the attractions of Black America, with its culture, music, entertainment traditions. Although at first the increasing number of visitors did not result in increased tourism spending, by now multiculturalism has become an economically attractive option, together with the saturation of the traditional tourism markets. Cultural tourism has gone beyond the visits to museums, theatres and high art events, and has started to include anthropological concern, with ethnicity and heritage being in the centre of this perception. A nice example of this shift is the 'I love New York' campaign in 2001, with its theme of diversity, and cultural connections to African-American, European, Asian, Hispanic, NativeAmerican ethnicities (Hoffmann, 2003).

Cultural, ethnic and heritage tourism in the Asia-Pacific Region has grown dramatically since the 1980s. Ethnic minority culture - including material and performed culture and traditions - has become a major focus of tourism not only in the developed world, but in China, as well (Doorne, Ateljevic, \& Bai, 2003). The system of global production and consumption has led to the homogenisation of cultures, and this generated a need to actively search for „differentness” by way of tourism (Sharpley, 1996). 
Ethnic attributes can be considered as an asset, and tourism can promote its restoration, preservation and fictional recreation (McCannell, 1992). Looking at the history of ethnicity an idea of the „us/they opposition” is prevalent as well as the double approaches of bio-genetic race and socio-genetic culture. Ethnicity in the 20th century most often focused on the biogenetic physical traits, as inherited features, distinguishing them from the cultural traits, which are of learned character.

Ethnic tourism and heritage tourism are closely linked, but while ethnic tourism points out differences of the host and the tourist community, heritage tourism focuses on one's own past (Blum, 2007). The experience of ethnic theme parks show, that tourists often view ethnic minorities as backward and primitive. The theoretical foundations of ethnic tourism are presented, illustrated by some good examples from the Far-East (Nate-Chei, 2009).

Ethnic diversity also contributes to the richness in religious architecture- cathedrals, mosques, temples -, as is illustrated by the example of Sydney, Australia (Collins \& Kunz, 2007). However, although Sydney is often referred to as "the world in one city”, the promotion of the metropolis as a tourism destination has rarely built on its diversity.

Immigrant communities have often greatly contributed to the cultural, artistic and economic stability of a host community (Landry \& Bianchini, 1995: p.28). Examples from the UK and Canada show that in transnational communities created by immigration, immigrants can often be viewed not only as passive recipients of welfare support but as active agents of regeneration of the economy (Shaw, 2007). This is illustrated by the success of Asian restaurants, the cultural festivals that celebrate the food, drinks, music, craftswork, of Pakistani, Indian, Caribbean, and other Afro-American traditions (Urry, 1990: p.44).

Although cultural diversity as a tourist attraction is a well accepted concept, relatively few studies have dealt with the empirical analysis of tourism and diversity interactions. One such example is the study by Das and DiRienzo (2009), on the relationship between the Travel and Tourism Competitiveness Index and ethnic fractionalisation. The Travel and Tourism Competitiveness Index computed by the World Economic Forum is an important information about the current performance and capacity of a country to be successful in tourism. The value of this index has been tested in a cross - country analysis of 127 countries to see, whether it has any relationship to ethnic or cultural diversity (Das \& DiRienzo, 2009). Findings showed, that there is a significant negative relationship between ethnic diversity as of 1985-2001 and the logarithm of TTCI for 2009, when relationship was controlled for economic freedom and level of democracy. However, the study revealed, that the interaction of ethnic diversity and per capita level of GDP is also significant. This means that higher incomes can mitigate the negative impact of higher ethnic diversity on tourism 
competitiveness. This is not surprising, considering the fact, that tourism competitiveness is closely related to the quality of the built and natural environment, transport facilities, general infrastructure, health care institutions, and many other factors which depend on nation-wide investments. These investments naturally depend on the level of national income, on the one hand, and on the general support of the society on such nation-wide investments. In a more fractionalised society this support is more difficult to achieve.

A country's religious affiliation is also important in destination choice for international tourism. A cross-country study of 164 countries (Fourie, Rossello, \& Santana Gallego, 2015), for the period 1995-2010, provided evidence that religious similarity have significant explanatory power in global tourism, and the presence of common religious minorities in the country has a positive impact on tourism flows. However, religious similarity was found to have a stronger positive effect. Australian tourists' intention to visit a particular country was found to be negatively correlated to the cultural or linguistic distance between the host and the home countries (Siew, Lee, and Soutar, 2007), even if adjusted for georgraphic distance.

Empirical research has revealed, that cultural and religious similarity is more beneficial for tourism performance, than multiculturality. The present paper attemtps to address this issue by statistical analyses of tourism performance and diversity data.

\section{METHODOLOGY AND DATA}

\section{General description of methodology and data}

The present paper uses demographic data and tourism indicators of 155 countries of the world to analyse possible relationships between tourism performance and ethnic, linguistic or religious fractionalisation. The number of countries involved were determined by data availability needed for the analysis.

For describing the ethnic and religious fragmentation of the studied countries the datasets of earlier research were taken: ethnic fragmentation indices for 2001 by Alesina and La Ferrara (2005), and by Fearon (2003) for 2001 or 2003. Linguistic diversity indices were available from Ethnologue (2016). Religious fractionalisation indices were used for 2001 by Alesina and LaFerrara (2005), and newer index was computed according to Greenberg's methodology for the present study based on the data published by the Pew Research Centre for the year 2010 (Pew Research Centre, 2012). For tourism data the World Bank database for the years 2014 and 2015, and the publications of the World Economic Forum (WEF, 2017) about the components of the Travel and Tourism Competitiveness Index (TTCI) were used for the years 2013, 2015 and 2017. Data on the population and GNI were downloaded 
from the United Nations Department of Economic and Social Affairs. National GNI data for 2014 and 2015 were used as published by the World Economic Forum (WEF, 2017). Finally, data on the year of independence were collected from the CIA Worl Factbook (CIA, 2017).

It has to be mentioned that the analyses were carried out for the years 2014 and 2015 for the indicators of tourism performance, while the ethnic and religious fractionalisation indices are much older. However, these social traits do not show rapid substantial changes, and their general character tends to be nearly the same for year by year. Therefore the results of the analysis can identify relationships of tourism performance and fractionalisation reflecting long-term tendencies which may only slightly change within the time span of a couple of years.

Statistical tests and graphical assessments were done by MS-EXCEL and by SPSS. The methods used were simple descriptive statistics, correlation between input, control and output variables, and regression analysis for input, control and output variables. Assessment of distributions and frequencies, as well as classification of countries into categories were also made by input and output variables. Details of the techniques will be presented in the Results section.

\section{Summary list of the data and variables were used in the analysis}

Diversity measures - Input indicators:

- Cultural Diversity Index (CDI) - by Fearon (2003);

- Ethnic Fragmentation Index (EFIA) - by Alesina and La Ferrara (2005);

- Religious Fragmentation Index (RFA) - by Alesina and La Ferrara (2005);

- Religious Fragmentation Index (RFIPew) - based on the data by Pew Research Centre (2012;

- Language Diversity Index (LDI) - by Ethnologue (2016)

\section{Control variables:}

- The year when the country became an independent state (IND YEAR) - by CIA World Factbook (2017), and its categorical variable (IND) as: IND =1: before 1900; IND=2: between 1901-1945; IND=3: between 1946-1989, IND=4: in 1990 or after) - CIA World Factbook (2017)

- Real GNI per capita for 2014 - WEF (2015) 
- Population of the country as \% of total world population (POP\%) - by UN DESA (2017).

Data on Tourism performance - Output indicators:

All the following data are derived from the database of the World Economic Forum (WEF, 2015, 2017)

- Data describing the importance of the country in the international tourism market:

- International Arrivals as \% of total international arrivals of the world (Arriv\%W)- 2014, 2015

- International Tourism Receipts as $\%$ of total international receipts of the world (Receipts\%W) - 2014, 2015

○ Travel and Tourism Competitiveness Index (TTCI) - 2015, 2017 (WEF, 2015, 2017)

- Derived indicators for comparing countries according to their role in world tourism:

Using the Population of country as \% of the world (Pop\%), and the GNI of the country as \% of total world GNI (GNI\%) for 2014 and 2015 two differences were computed:

$\circ$ The difference of the country share in international tourism arrivals of the world and its share in world population: DiffArriv= Arriv\%W - Pop\%; for 2014, 2015

- The difference of the country share in international tourism receipts of the world and its share in world total GNI: DiffRec= Receipts\%W - GNI\%; for 2014,2015

\begin{abstract}
ANALYSIS
The purpose of the analysis presented in the paper is to examine the countries of the world regarding their performance in tourism, and find out if their performance is related in any way (positive or negative) to the ethnic, linguistic or religious structure of their society.

The analysis uses data on the actual tourism performance of the countries analysed, meausing it on the one hand, as the percentage share of the country in the overall performance of world tourism - more precisely, in the total number of international arrivals in the world, and in the total international tourism receipts generated in the world. The other aspect of tourism performance is the importance of tourism in the national economies - which is measured by total international arrivals per inhabitant in the country, and total share of international tourism receipts in the GNI of the country. Besides the actual tourism performance (arrivals and receipts actually achieved), the tourism competitiveness of
\end{abstract}


countries will also be looked at. Travel and tourism competitive indices (TTCI) as computed annually by the World Economic Forum measure not only the actual arrival and receipt data, employment and GDP generated by tourism, but many other factors that make the country more attractive to tourists, or better capable of catering for tourist needs, and guarantee their health, safety and security. This way TTCI is a measure of not so much the actual tourism performance, but incorporates elements of potential success in tourism.

The present analysis will look at two aspects. The share of a country in the world total values of tourism performance adjusted for the size of the country can point out good performers and poor performers. The TTCI values (for several years), and their changes reflect the opportunities of a country to develop into a successful actor in world tourism. The exciting question is, whether these features have any relations to the sociocultural structure of the society regarding its ethnic, linguistic or religious heterogeneity or homogeneity.

The analysis is carried out in the following structure: first an overview of the variables will be presented, including the input variables (diversity measures), the output variables (measures of tourism performance and competitiveness), and a few control variables (level of general development measured by per capita GNI, and size of the country measured by its population as a percentage of the total world population).

The second step is to find correlations between the variable pairs - input, output and control variables. Third, an overall regression relationship is looked for between the output variables (tourism performance and competitiveness indicators) and diversity indicators and control variables.

The fourth step is to look at groups of countries according to their actual tourism performance and look for typical heterogeneity or diversity patterns within the groups of countries within each group.

\section{Descriptive analysis}

Diversity indices are available for altogether 155 countries. The values vary between 0 and 1 . As descriptive statistics show (Table 1), the mean value of heterogeneity ranges from 0.293 (RFIPew) to 0.461 (LDI), the minimum values are 0 or very close to it for all types of diversity, the maximum values vary in the range from 0.733 (CDI) to 0.988 (LDI).

Skewness values are close to zero, and kurtosis values are close to -1 , which is an indication that the diversity indicators do not follow a normal distribution. A normal distribution should have near-zero skewness and kurtosis, and if the absolute values of these statistics are more than twice the standard error, then data are not of a normal distribution. It is 
also worth noticing, that standard deviations of the diversity indices are smaller than mean values.

Table 1 Descriptive Statistics for Diversity Indicators

\begin{tabular}{|l|c|c|r|r|r|r|r|r|r|}
\hline & $\mathrm{N}$ & Min & \multicolumn{1}{c|}{ Max } & Mean & Std. Dev & Skewness & $\begin{array}{c}\text { Skewness } \\
\text { Std. Error }\end{array}$ & Kurtosis & $\begin{array}{c}\text { Kurtosis } \\
\text { Std. Error }\end{array}$ \\
\hline CDI & 155 & .0000 & .7330 & .3047 & .2105 & .186 & .195 & -1.184 & .387 \\
EFIA & 155 & .0000 & .9302 & .4593 & .2560 & -.081 & .195 & -1.189 & .387 \\
RFA & 155 & .0023 & .8603 & .4377 & .2314 & -.183 & .195 & -1.081 & .387 \\
RFIPew & 155 & .0020 & .7920 & .2926 & .1940 & .289 & .195 & -.960 & .387 \\
LDI & 155 & .0000 & .9880 & .4612 & .3007 & .050 & .195 & -1.295 & .387 \\
\hline
\end{tabular}

Descriptive statistics for the output variables are shown in Table 2. Considering the variables measuring the importance of the countries in world tourism, the average value for the countrywise international arrivals compared to the world total is $0.65-0.75 \%$, with maximum values around $8 \%$, while regarding international tourism receipts the average is similar to arrivals (around $0.73-0.78 \%$ of the word total), but the maximum value is twice as high, 17.619.4\%. The Tourism and Travel Competitiveness index (on a scale of 1 to 7) has average values of 3.7-3.8, while the maximum index values are 5.3-5.4, none of the analysed countries are closer to the theoretical maximum of 7.

Table 2 Descriptive Statistics for the Output Variables of Tourism Performance

\begin{tabular}{|l|l|l|l|l|l|l|l|l|l|}
\hline & & & & & & & Skewness & & $\begin{array}{l}\text { Kurtosis } \\
\text { Std. Error }\end{array}$ \\
& $\mathrm{N}$ & Min & Max & Mean & Std. Dev & Skewness & Std. Error \\
\hline Arriv\%W2014 & 155 & .00 & 8.03 & .6452 & 1.27683 & 3.550 & .195 & 14.298 & .387 \\
Arriv\%W2015 & 134 & .00 & 7.78 & .7463 & 1.33845 & 3.224 & .209 & 11.566 & .416 \\
Receipts\%W2014 & 137 & .00 & 17.59 & .7299 & 1.84497 & 6.453 & .207 & 53.016 & .411 \\
Receipts\%W2015 & 129 & .00 & 19.41 & .7752 & 2.04207 & 6.751 & .213 & 56.271 & .423 \\
\hline DiffArriv_2014 & 151 & -16.47 & 7.15 & .0115 & 2.08582 & -4.786 & .197 & 38.529 & .392 \\
DiffArriv_2015 & 142 & -17.00 & 6.79 & .0361 & 2.16857 & -4.945 & .203 & 38.464 & .404 \\
DiffRec_2014 & 137 & -5.63 & 3.12 & .0031 & .97890 & -3.312 & .207 & 19.321 & .411 \\
DiffRec_2015 & 125 & -5.47 & 3.31 & .0065 & .94808 & -2.811 & .217 & 16.850 & .430 \\
\hline TTCI2017 & 127 & 2.44 & 5.43 & 3.7932 & .70159 & .318 & .215 & -.611 & .427 \\
TTCI2015 & 129 & 2.43 & 5.31 & 3.7178 & .69630 & .347 & .213 & -.695 & .423 \\
\hline
\end{tabular}

Comparing the importance of each country in world tourism to its size (population for DiffArriv or total GNI for DiffRec), the average values are around 0 (more tourism-oriented countries and less tourism-oriented countries balance their differences). The maximum values are around $+7 \%$ for arrivals and $+3 \%$ for receipts (meaning, that the most important country has $7 \%$ higher share in tourism arrivals than in the world population, and $3 \%$ higher share in tourism receipts than in GNI of the world), while the minimum values are $(-16.5 \%)-(-$ $17.0 \%)$ in arrivals, and (-5.5\%)-(-5.6\%) for receipts. 
It is worth noticing, that Skewness and Kurtosis values are very high absolute values except for TTCI, meaning that these variables are probably not of normal distributions. This must be considered in further statistical tests.

\section{Correlations}

To reveal relationships between tourism performance and sociocultural or religious heterogeneity the bivariate (pairwise) correlations will be looked at. Before doing this, it is useful to have a look at correlations among the five diversity indicators is useful to find out if there might be some collinearity among these variables.

\section{Correlations of the input variables}

As is seen in Table 3, there is quite strong positive pairwise correlation among cultural (CDI), ethnic (EFIA) and linguistic (LDI) diversity indices, indicating a certain level of collinearity. Weak, but significant positive correlations were found between religious diversity of 2001 (RFA) and each of CDI, EFIA, LDI. Finally, a medium positive significant correlation was found between the two religious diversity indicators, RFA and RFIPew, which is not surprising, assuming that the religious heterogeneity situation in 2001 (RFA) should have some relationship to the situation in 2010 (RFIPew).

Table 3 Correlation Among the Diversity Indices

\begin{tabular}{|l|l|r|r|r|r|r|}
\hline \multicolumn{2}{|c|}{ Spearman's rho (N=155) } & \multicolumn{1}{c|}{ CDI } & \multicolumn{1}{c|}{ EFIA } & \multicolumn{1}{c|}{ LDI } & \multicolumn{1}{c|}{ RFA } & RFIPew \\
\hline \multirow{2}{*}{ CDI } & Correlation Coefficient & 1.000 & $.702^{* *}$ & $.673^{* *}$ & $.178^{*}$ & .114 \\
\cline { 2 - 7 } & Sig. (2-tailed) &. & .000 & .000 & .027 & .159 \\
\hline \multirow{2}{*}{ EFIA } & Correlation Coefficient & .702 & 1.000 & $.706^{* *}$ & $.210^{* *}$ & .114 \\
\cline { 2 - 7 } & Sig. (2-tailed) & .000 & & .000 & .009 & .010 \\
\hline \multirow{2}{*}{ RDI } & Correlation Coefficient & $.673^{* *}$ & $.706^{* *}$ & 1.000 & $.302^{* *}$ & .898 \\
\cline { 2 - 7 } & Sig. (2-tailed) & .000 & .000 &. & .000 & .125 \\
\hline \multirow{2}{*}{ RFIPew } & Correlation Coefficient & $.178^{*}$ & $.210^{* *}$ & $.302^{* *}$ & 1.000 & $.565^{* *}$ \\
\cline { 2 - 7 } & Sig. (2-tailed) & .027 & .009 & .000 &. & .000 \\
\cline { 2 - 7 } & Correlation Coefficient & .114 & .010 & .124 & $.565^{* *}$ & 1.000 \\
\cline { 2 - 7 } & Sig. (2-tailed) & .159 & .898 & .125 & .000 &. \\
\hline
\end{tabular}

** Correlation is significant at the 0.01 level (2-tailed); * Correlation is significant at the 0.05 level (2-tailed).

As collinearity of the CDI -EFIA-LDI variables and of the RFA - RFIPew variables may cause problems in some of the statistical tests, two new variables are introduced: CultDivMax $=\max (C D I, E F I A, L D I)$ gives the largest sociocultural diversity value for each country, while ReligDivMax $=\max ($ RFA,RFIPew) gives the largest of the two religious 
diversity measures. In some of the analyses, instead of using all the three sociocultural variables, or both of the religious variables together, the CultDivMax or the ReligDivMax variables will be used.

\section{Correlations of the output indicators to the input indicators}

Bivariate correlations between the output indicators and the diversity indicators revealed the following patterns (Table 4):

- Ethnic diversity (EFIA) shows significant, but not too strong negative correlations to Arrivals values; i.e. the more diverse countries have less international tourist arrivals.

- Religious diversity (RFIPew) has significant, but weak positive correlations to Receipts as world \% values, i.e. the more religious diversity goes together with higher tourism receipts. The other religious diversity index, RFA, has no correlation to arrivals, and weak positive significant correlation to Receipts values, i.e when religious diversity is higher, then the difference between the share of the country in world tourism receipts compared to its share in world GNI is smaller.

- Language diversity (LDI) has weak significant negative correlations to arrivals, i.e. the linguistically more diverse countries have lower share in international tourism arrivals compared to their population size.

Table 4 Correlations of Tourism Performance and Diversity

\begin{tabular}{|c|c|c|c|c|c|c|}
\hline \multicolumn{2}{|c|}{ Spearman's rho } & CDI & EFIA & LDI & RFA & $\begin{array}{c}\text { RFIPe } \\
\mathbf{w}\end{array}$ \\
\hline \multirow[t]{2}{*}{$\begin{array}{l}\text { Arriv\%W2014, } \\
\qquad \mathrm{N}=155\end{array}$} & $\begin{array}{l}\text { Correlation } \\
\text { Coefficient }\end{array}$ & $-.301^{* *}$ & $-.490^{* *}$ &.$- .357^{* *}$ & -.084 & .112 \\
\hline & Sig. (2-tailed) & .000 & .000 & .000 & .296 & .167 \\
\hline \multirow[t]{2}{*}{$\begin{array}{c}\text { Arriv\%W2015, } \\
\qquad \mathrm{N}=134\end{array}$} & $\begin{array}{l}\text { Correlation } \\
\text { Coefficient }\end{array}$ & $-.272^{* *}$ & $-.479^{* *}$ & $-.332^{* *}$ & $-.145^{\#}$ & .046 \\
\hline & Sig. (2-tailed) & .001 & .000 & .000 & .094 & .597 \\
\hline \multirow[t]{2}{*}{$\begin{array}{l}\text { Receipts\%W2014, } \\
\qquad \mathbf{N}=\mathbf{1 3 7}\end{array}$} & $\begin{array}{l}\text { Correlation } \\
\text { Coefficient }\end{array}$ & $-.199^{*}$ & $-.436^{* *}$ & $-.293^{* *}$ & -.078 & $.188^{*}$ \\
\hline & Sig. (2-tailed) & .019 & .000 & .001 & .366 & .028 \\
\hline \multirow[t]{2}{*}{$\begin{array}{c}\text { Receipts\%W2015, } \\
\qquad \mathbf{N}=\mathbf{1 2 9}\end{array}$} & $\begin{array}{l}\text { Correlation } \\
\text { Coefficient }\end{array}$ & $-.173^{\#}$ & $-.403^{* *}$ & $-.266^{* *}$ & -.057 & $.234^{* *}$ \\
\hline & Sig. (2-tailed) & .051 & .000 & .002 & .521 & .008 \\
\hline
\end{tabular}

**. Correlation is significant at the 0.01 level (2-tailed); *. Correlation is significant at the 0.05 level (2-tailed). \#: Correlation is significant at the 0.1 level (2-tailed).

Therefore it may be suspected, that there is some relationship between sociocultural and religious diversity on the one hand, and the tourism performance indicators, on the other, and 
this relationship is mainly of adverse character for ethnic and language diversity, and positive for religious diversity. This means that higher ethnic or linguistic diversity coincides with lower performance, while higher religious diversity goes together with better tourism performance. However, these bivariate correlation coefficients are small, their absolute value ranges from 0.137 to -0.290 , therefore these relationships may be quite weak.

\section{Correlations to TTCI}

The TTCI values (Table 5) have

- a weak to medium significant negative correlation to the sociocultural diversity indicators (CDI-EFIA -LDI - CultDivMax)

- a weak positive significant correlation to RFIPew

- a strong positive significant correlation to GNI per capita.

- a weak positive significant correlation to Pop percent.

Table 5 Correlations of TTCI to Diversity Indicators and Control variables

\begin{tabular}{|c|c|c|c|c|c|c|c|c|c|c|}
\hline \multicolumn{2}{|c|}{ Spearman's rho } & $\begin{array}{c}\text { Pop } \\
\%\end{array}$ & $\begin{array}{l}\text { GNI } \\
2014 \\
\end{array}$ & CDI & EFIA & LDI & $\begin{array}{c}\mathbf{R F} \\
\mathbf{A}\end{array}$ & $\begin{array}{c}\text { RFIP } \\
\text { ew }\end{array}$ & $\begin{array}{l}\text { Cult } \\
\text { Div } \\
\text { Max }\end{array}$ & $\begin{array}{c}\text { Reli } \\
\text { g } \\
\text { Div } \\
\text { Max } \\
\end{array}$ \\
\hline \multirow{2}{*}{$\begin{array}{c}\text { TTCI201 } \\
5, \\
\mathbf{N}=129\end{array}$} & $\begin{array}{l}\text { Correlation } \\
\text { Coefficient }\end{array}$ & .114 & $.835^{* *}$ & $-.165^{\#}$ & $.446^{* *}$ & $.337^{* *}$ & .014 & $.241^{* *}$ & $.403^{* *}$ & .037 \\
\hline & Sig. (2-tailed) & .199 & .000 & .061 & .000 & .000 & .877 & .006 & .000 & .678 \\
\hline \multirow{2}{*}{$\begin{array}{c}\text { TTCI201 } \\
7, \\
\mathbf{N}=127\end{array}$} & $\begin{array}{l}\text { Correlation } \\
\text { Coefficient }\end{array}$ & $.170^{\#}$ & $.819^{* * *}$ & $-.197^{*}$ & $.477^{-*}$ & $.372^{* *}$ & .023 & $.243^{* *}$ & $.441^{* *}$ & .003 \\
\hline & Sig. (2-tailed) & .056 & .000 & .027 & .000 & .000 & .793 & .006 & .000 & .973 \\
\hline \multirow[t]{2}{*}{$\begin{array}{c}\text { Pop \%, } \\
\text { N=155 }\end{array}$} & $\begin{array}{l}\text { Correlation } \\
\text { Coefficient }\end{array}$ & 1.000 & -.029 & -.023 & -.022 & .071 & .072 & -.074 & .063 & .075 \\
\hline & Sig. (2-tailed) & & .716 & .772 & .790 & .380 & .371 & .361 & .433 & .352 \\
\hline \multirow{2}{*}{$\begin{array}{c}\text { GNI2014 } \\
\mathrm{N}=\mathbf{1 5 5}\end{array}$} & $\begin{array}{l}\text { Correlation } \\
\text { Coefficient }\end{array}$ & -.029 & 1.000 & $.266^{* *}$ & $.519^{-*}$ & $.399^{* *}$ & $\begin{array}{r}- \\
.027\end{array}$ & $.239^{* *}$ & $.489^{-\bar{*}}$ & .008 \\
\hline & Sig. (2-tailed) & .716 & & .001 & .000 & .000 & .743 & .003 & .000 & .923 \\
\hline
\end{tabular}

**. Correlation is significant at the 0.01 level (2-tailed); *. Correlation is significant at the 0.05 level (2-tailed).

\#: Correlation is significant at the 0.1 level (2-tailed).

\section{Multiple regression for all countries}

As bivariate correlations revealed some significant correlations between output and input variables, but none too strong, the next idea was to use a combination of them to estimate output indicators, i.e. tourism performance as arrivals and receipts, to see their joint impact, and possibly, interactions.

As it was seen earlier, there is a strong positive correlation among the sociocultural diversity indicators, CDI-EFIA-LDI, therefore at least one of them should be omitted. At first 
the CDI variable will be omitted, as language and ethnicity can largely explain differences in culture.

RFA, the older religious diversity indicator has low correlation to sociocultural diversity indices, and medium positive correlation to RFIPew, the other religious indicator. This latter does not correlate to the sociocultural diversity indices, therefore it will be retained in the model, and RFA will be omitted.

However, control variables were also introduced: GNI per head and Population percent. At the first model tests the Independence year, and Region were also introduced as dummies, but none of these had any significant impact, therefore the following analyses do not deal with them.

Dependent variables were: LnTTCI - for 2015 and 2017 as measures of the international potentials of the countries; and LnArriv\%W ad LnReceipts\%W for 2014 and 2015 as measures of the actual performance in world tourism. Including all the 5 input and the above 2 control variables in the models, the following results were generated:

\section{TTCI (or, InTTCI) as Dependent variable}

In the following models multiple linear regression is applied. In order to have valid results, several assumptions have to be tested.

- There is not too high multicollinearity among independent variables - this is tested by the regression procedure itself, the VIF values have to remain under 10 .

- The residuals follow a normal distribution - this is automatically follows from the leastsquares method used in fitting a regression line.

- The residuals show no autocorrelation (only for time series data), and their mean values are zero - this was also tested by the regression procedure graphically, and by descriptive statistics of residuals.

- The homoscedasticity of the residuals: plotting the standardised residuals against the standardised predicted values, the values are evenly scattered around zero - this was also tested during the regression procedure by the scatterplot of residuals.

Model 1: Following the example of Das and DiRienzo (2009) the model was tested with $\operatorname{lnTTCI2015}$ and $\operatorname{lnTTCI} 2017$ as output variables respectively.

Input variables were: EFIA and CultDivMax. The choice of LDI was also tested.

Control variables were: GNI and Pop\% 
Results are shown in Table 6. VIF values were of 1.01 to 1.1 for the independent variables, i.e. multicollinearity does not reach critical levels. All the model versions complied with the assumptions required for the regression analysis procedure.

Table 6 Summary of regression models with $\ln$ TTCI

\begin{tabular}{|c|c|c|c|c|c|c|}
\hline & \multicolumn{3}{|c|}{$\begin{array}{l}\text { Model 1a - Dependent : } \\
\text { InTTCI2015 }\end{array}$} & \multicolumn{3}{|c|}{$\begin{array}{l}\text { Model 1b - Dependent: } \\
\text { InTTCI2017 }\end{array}$} \\
\hline Adjusted $\mathrm{R}^{2}$ & \multicolumn{3}{|c|}{.594} & \multicolumn{3}{|c|}{.598} \\
\hline Regression F & \multicolumn{3}{|c|}{$\mathrm{F}=63.351(\mathrm{df}=3.125) \quad$ sig $=.000$} & \multicolumn{3}{|c|}{$\mathrm{F}=63.469(\mathrm{df}=3.123) . \quad \mathrm{sig}=.000$} \\
\hline & $B^{*}$ & Beta** & sig & $B^{*}$ & Beta** & sig \\
\hline (Constant) & 1.239 & & .000 & 1.245 & & .000 \\
\hline CultDivMax & -.170 & -.230 & .000 & -.169 & -.273 & .000 \\
\hline GNIP2014 & $7.239 \mathrm{E}-6$ & 0.665 & .000 & $\begin{array}{l}7.134 \mathrm{E}- \\
6\end{array}$ & .659 & .000 \\
\hline \multirow[t]{2}{*}{ Pop percent } & .017 & .217 & .000 & .019 & .245 & .000 \\
\hline & \multicolumn{3}{|c|}{$\begin{array}{c}\text { Model 1c- Dependent: } \\
\text { InTTCI2015 }\end{array}$} & \multicolumn{3}{|c|}{$\begin{array}{l}\text { Model 1d- Dependent: } \\
\text { InTTCI2017 }\end{array}$} \\
\hline \multirow{3}{*}{$\begin{array}{ll}\text { Adjusted }^{2} & \\
\text { Regression } & \mathrm{F} \\
\text { (df) } & \\
\end{array}$} & \multicolumn{3}{|c|}{.573} & \multicolumn{3}{|c|}{.559} \\
\hline & \multicolumn{3}{|c|}{$\mathrm{F}=44.003(\mathrm{df}=4.124) . \mathrm{sig}=.000$} & \multicolumn{3}{|c|}{$\mathrm{F}=40.925(\mathrm{df}=4.124) . \quad \mathrm{sig}=.000$} \\
\hline & $B^{*}$ & Beta $^{* *}$ & $\operatorname{sig}$ & $B^{*}$ & Beta** $^{* *}$ & $\operatorname{sig}$ \\
\hline Constant & 1.214 & & .000 & 1.240 & & .000 \\
\hline EFIA & -.144 & -.192 & .003 & -.155 & -.209 & .002 \\
\hline RFIPew & .015 & .015 & .817 & .027 & .027 & .677 \\
\hline GNI & $7.145 \mathrm{E}-6$ & .656 & .000 & $6.765 \mathrm{E}-6$ & .625 & .000 \\
\hline \multirow[t]{2}{*}{ PopPercent } & .014 & .176 & .003 & .015 & .191 & .002 \\
\hline & \multicolumn{3}{|c|}{$\begin{array}{c}\text { Model 1e - Dependent : } \\
\text { InTTCI2015 }\end{array}$} & \multicolumn{3}{|c|}{$\begin{array}{l}\text { Model 1f - Dependent : } \\
\text { InTTCI2017 }\end{array}$} \\
\hline Adjusted $\mathrm{R}^{2}$ & \multicolumn{3}{|c|}{.601} & \multicolumn{3}{|c|}{.598} \\
\hline Regression F & \multicolumn{3}{|c|}{$\mathrm{F}=65.274(\mathrm{df}=3.125) \quad \mathrm{sig}=.000$} & \multicolumn{3}{|c|}{$\mathrm{F}=63.469(\mathrm{df}=3.123) . \operatorname{sig}=.000$} \\
\hline & $B^{*}$ & Beta** $^{* *}$ & sig & $B^{*}$ & Beta** $^{*}$ & sig \\
\hline Constant & 1.214 & - & .000 & 1.245 & & .000 \\
\hline LDI & -.152 & -.241 & .000 & -.169 & -.273 & .000 \\
\hline GNI & $7.458 \mathrm{E}-6$ & .685 & .000 & $\begin{array}{l}7.134 \mathrm{E}- \\
6\end{array}$ & .659 & .000 \\
\hline PopPercent & .018 & .223 & .000 & .019 & .245 & .000 \\
\hline
\end{tabular}

$*$ : B is the unstandardised coefficient, $* *$ : Beta is the standardised coefficient

VIF values for all model versions were in the range of 1.0-1.5. Standardised residuals had mean=0.00, st.deviation varied between 0.98 and 0.99 , and followed a homoscedastic pattern.

Results for Model 1:

All the tested sociocultural diversity measures had significant negative impact on lnTCCI, except RFIPew. This latter showed positive impact but not on a significant level. Therefore we may state that tourism competitiveness will decrease when ethnic, linguistic, or cultural diversity is higher. However, this may not be true for religious diversity, as its impact was not significant in any variable combination. It is also established, that the per capita income level, 
and the size of the population are both positively influence tourism competitiveness, the larger, or richer the country, the more competitive it is in the international tourism market.

As GNI turned out to be a variable of crucial importance in all the Model 1 regressions, the question arises whether its level can influence the impact of the diversity indicators themselves, to any extent. Therefore interaction terms were introduced for the significant diversity indices. The GNI x CultDivMax, GNI x EFIA, GNI x LDI interaction terms were introduced to the respective regression equations. In order to avoid collinearity of the interaction variable and the respective independent variables, the interaction terms were computed by way of centering the respective variables (i.e. deducting their respective means from each of them) before multiplying them. Table 7 summarises the results of the regressions.

Model 2: Interaction between GNI and the selected input variable (GNI x EFIA, GNI $x$ CultDivMax, GNIx LDI) was introduced, when the impact of the input variable was found to be significant.

Table 7 Summary of regression models with $\ln$ TTCI and interaction

\begin{tabular}{|c|c|c|c|c|c|c|}
\hline & \multicolumn{3}{|c|}{$\begin{array}{l}\text { Model 2a - Dependent: } \\
\text { InTTCI2015 }\end{array}$} & \multicolumn{3}{|c|}{$\begin{array}{l}\text { Model 2b - Dependent: } \\
\text { InTTCI2017 }\end{array}$} \\
\hline Adjusted $\mathrm{R}^{2}$ & \multicolumn{3}{|c|}{, 601} & \multicolumn{3}{|c|}{,595 } \\
\hline \multirow[t]{2}{*}{ Regression F } & \multicolumn{3}{|c|}{$\mathrm{F}=49.75(\mathrm{df}=4,124) \quad$ sig $=.000$} & \multicolumn{3}{|c|}{$\mathrm{F}=47.260(\mathrm{df}=4,122), \quad \mathrm{sig}=, 000$} \\
\hline & $B^{*}$ & $B^{*}$ & $B^{*}$ & $B^{*}$ & Beta** & sig \\
\hline (Constant) & 1,231 & &, 000 & 1,269 & &, 000 \\
\hline CultDivMax & -0.164 & -0.211 & ,000 & -0.188 & -0.257 &, 000 \\
\hline GNIP2014 & $\begin{array}{r}7.198 \mathrm{E}- \\
6 \\
\end{array}$ & 0.661 &, 000 & $\begin{array}{r}6.829 \mathrm{E}- \\
6 \\
\end{array}$ & 0.631 & 000 \\
\hline Population percent & 0.017 & 0.221 &, 000 & 0.018 & 0.234 &, 000 \\
\hline \multirow[t]{2}{*}{$\begin{array}{ll}\text { Interact GNI } & \mathrm{x} \\
\text { CultDivMax } & \end{array}$} & $\begin{array}{r}-4.647 \mathrm{E}- \\
6\end{array}$ & -0.104 & ,068 & $\begin{array}{r}-3.766 \mathrm{E}- \\
6\end{array}$ & -0.084 & , 144 \\
\hline & \multicolumn{3}{|c|}{$\begin{array}{c}\text { Model 2c - Dependent: } \\
\text { InTTCI2015 }\end{array}$} & \multicolumn{3}{|c|}{$\begin{array}{c}\text { Model 2d- Dependent: } \\
\text { InTTCI2017 }\end{array}$} \\
\hline \multirow{3}{*}{$\begin{array}{l}\text { Adjusted } \mathrm{R}^{2} \\
\text { Regression } \mathrm{F}(\mathrm{df}) \\
\end{array}$} & \multicolumn{3}{|c|}{,580 } & \multicolumn{3}{|c|}{,564 } \\
\hline & \multicolumn{3}{|c|}{$F=36.361(d f=5,123), \operatorname{sig}=, 000$} & \multicolumn{3}{|c|}{$\mathrm{F}=33.599(\mathrm{df}=5,121), \mathrm{sig}=, 000$} \\
\hline & $B^{*}$ & Beta** & sig & $B^{*}$ & Beta** & sig \\
\hline Constant & 1,212 & & 0.000 & 1.236 & & 0.000 \\
\hline EFIA & -0.014 & -0.187 & 0.004 & -0.149 & -0.200 & 0.003 \\
\hline RFIPew & -0.001 & -0.001 & 0.982 & 0.011 & 0.011 & 0.869 \\
\hline GNI & $\begin{array}{r}6.994 \mathrm{E}- \\
6\end{array}$ & 0.643 & 0.000 & $6.665-6$ & 0.616 & 0.000 \\
\hline PopPercent & 0.014 & 0.184 & 0.002 & 0.015 & 0.200 & 0.001 \\
\hline Interact GNI x EFIA & $\begin{array}{r}-4.545 \mathrm{E}- \\
6\end{array}$ & -0.102 & 0.087 & $\begin{array}{r}-4.205 \mathrm{E}- \\
6\end{array}$ & -0.095 & 0.123 \\
\hline
\end{tabular}


Table 7 (continued)

\begin{tabular}{|l|c|c|c|c|c|c|}
\hline & \multicolumn{2}{|c|}{$\begin{array}{c}\text { Model 2e - Dependent: } \\
\text { InTTCI2015 }\end{array}$} & \multicolumn{2}{c|}{$\begin{array}{c}\text { Model 2f - Dependent : } \\
\text { InTTCI2017 }\end{array}$} \\
\hline Adjusted R & \multicolumn{2}{|c|}{, 617} & \multicolumn{3}{c|}{, 610} \\
\hline Regression F (df) & \multicolumn{3}{|c|}{$\mathrm{F}=52,516(\mathrm{df}=4,124)$, sig=,000 } & \multicolumn{2}{c|}{$50.364(\mathrm{df}=4,122)$, sig=,000 } \\
\hline & $B^{*}$ & Beta $^{* *}$ & sig & $B^{*}$ & Beta $^{*}$ & sig \\
\hline Constant & 1.209 & - & 0.000 & 1.234 & & 0.000 \\
\hline LDI & -0.158 & -0.251 & 0.000 & -0.174 & -0.280 & 0.000 \\
\hline GNI & $\begin{array}{c}7.599 \mathrm{E}- \\
6\end{array}$ & 0.698 & 0.000 & $\begin{array}{c}7.290 \mathrm{E}- \\
6\end{array}$ & 0.673 & 0.000 \\
\hline PopPercent & 0.017 & 0.213 & 0.000 & 0.018 & 0.237 & 0.000 \\
\hline Interact GNI $x$ LDI & $-5.671 E-6$ & -0.137 & 0.014 & $-5.133 E-$ & -0.125 & 0.028 \\
\hline
\end{tabular}

*: B is the unstandardised coefficient, **: Beta is the standardised coefficient

VIF values for all model versions were less than 1.5. Standardised residuals had mean $=0.00$, st.deviation varied between 0.98 and 0.99 , and followed a homoscedastic pattern.

\section{Results for Model 2:}

Similar to the Model 1 series, the assumptions needed for applying multiple regression were tested. VIF values were all smaller tha. 1.5 independent variables, i.e. multicollinearity does not reach critical levels, and the assumptions for the standardised residuals also complied with requirements.

As is shown in Table 7, altogether, all of the models turned out to give a significant estimation, with adjusted R2 values above 0.55. Generally, a significant negative impact of the sociocultural diversity indices remained valid, but the interaction term turned out to be significant only for LDI (Model 2e and $2 \mathrm{f}$ in Table 7.). Therefore, no impact was found for the interaction between the ethnic or cultural diversity index and GNI. However, a small negative significant impact was identified for the interaction of GNI x LDI, i.e. a medium enhancing interaction effect was found for language diversity and per capita income. This means, that when there is language diversity, its impact is more negatively felt in countries with higher per capita incomes.

The model versions without interaction terms are quite similar to Das \& DiRienzo (2009), in which the ethnic diversity index had a negative impact on the Tourism and Travel Competitiveness index, GNI per capita and Population had positive impacts. However, regarding the mitigating effects of interaction, our results are just the opposite of what Das and DiRienzo found for EFIA.

This means, that GNI did not have a mitigating effect in relation to sociocultural diversity, and in the case of language diversity larger per capita incomes actually enhanced the negative 
effect of language diversity on competitiveness. RFIPew had no significant impact, it had no effect on tourism competitiveness.

\section{Dependent variable: Arriv \%W, Receipt \%W}

When analysing Arriv\%W ad Receipts\%W as dependent variables, results are very similar to the TTCI regressions. Again, sociocultural diversity turned out to be of negative impact on arrivals and tourism receipts, and no significant interaction was identified with GNI. As results were similar with independent variables CultDivMax, EFIA, and LDI, and for the years 2014 and 2015, only the 2014 data and the variable EFIA are presented below. Interaction terms were not found to be significant for any of the diversity indicators, not even for LDI.

Table 8 Regression models with interaction

\begin{tabular}{|l|c|c|c|c|c|c|}
\hline & \multicolumn{3}{|c|}{$\begin{array}{c}\text { Model 3a-Dependent : } \\
\text { InArriv\%W_2014 }\end{array}$} & \multicolumn{3}{c|}{$\begin{array}{c}\text { Model 3b- Dependent : } \\
\text { InRec\%W_2014 }\end{array}$} \\
\hline Adjusted $\mathrm{R}^{2}$ & \multicolumn{3}{|c|}{0.494} & \multicolumn{3}{c|}{0.465} \\
\hline $\begin{array}{l}\text { Regression } \\
(\mathrm{df})\end{array}$ & $\mathrm{F}$ & \multicolumn{2}{|c|}{$\mathrm{F}=33.996(\mathrm{df}=4.131) . \mathrm{sig}=.000$} & $30.55250 .364(\mathrm{df}=4.132)$. sig=.000 \\
\hline & $B^{*}$ & Beta** & sig & $B^{*}$ & Beta** & sig \\
\hline Constant & -2.164 & & .000 & -2.836 & & .000 \\
\hline EFIA & -1.116 & -.163 & .023 & -1.257 & -.149 & .030 \\
\hline GNI & $6.669 \mathrm{E}-05$ & .599 & .000 & $6.885 \mathrm{E}-05$ & .550 & .000 \\
\hline PopPercent & .200 & .268 & .000 & .270 & .297 & .000 \\
\hline $\begin{array}{l}\text { Interact } \\
\text { xEFIA }\end{array}$ & $5.938 \mathrm{E}-05$ & .133 & .053 & $-3.219 \mathrm{E}-05$ & -.063 & .326 \\
\hline
\end{tabular}

For notations see Table 7

Therefore we may conclude, that there is a significant negative impact of sociocultural diversity indicators on the actual tourism performance of countries, with respect to their weight and importance in the world tourism market.

\section{COUNTRY GROUPINGS BY TOURISM PERFORMANCE}

However, the question arises, whether these overall results may hide important differences among countries, i.e. some marked differences between touristically active and important countries and touristically not so important countries. Therefore new variables were introduced to measure the performance of the countries in this respect.

- DiffArriv_2014 $($ and 2015) $=$ Arrivals \% of World - Population \% 
- DiffRec_2014 (and 2015) = Receipts \% of World - GNI \% of World

DiffArriv measures the percentage difference of the country share in international arrivals in the world minus the country share in the total world population. A positive value indicates that the country receives more international tourists than would be expected if arrivals were proportional to its population. Similarly, DiffRec meaures the percentage difference of the country share in world tourism receipts minus the country share in the total GNI of the world. Again, a positive value means that the countr y receives a higher share in tourism receipts than its share in total world GNI.

As histograms show in Figure 1, the differences move within the range of $(-5)-(+10)$ percentage points for DiffArriv for both years, and in $(-4)-(+4)$ percentage point for DiffRec for both years, with two countries being outliers in the lower end of their respective ranges. The two outliers for DiffArriv are China and India while the outliers for DiffRec are China and Japan. For these reasons these three countries will be handled as outliers and will not be included in the following analyses.

Figure 1 Histograms of DiffArriv and DiffRec variables
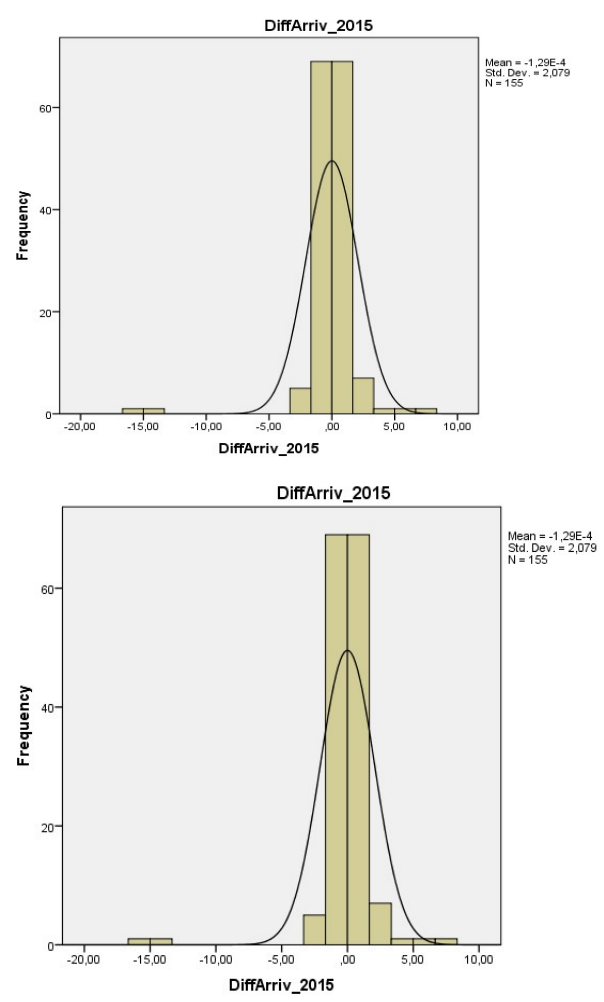
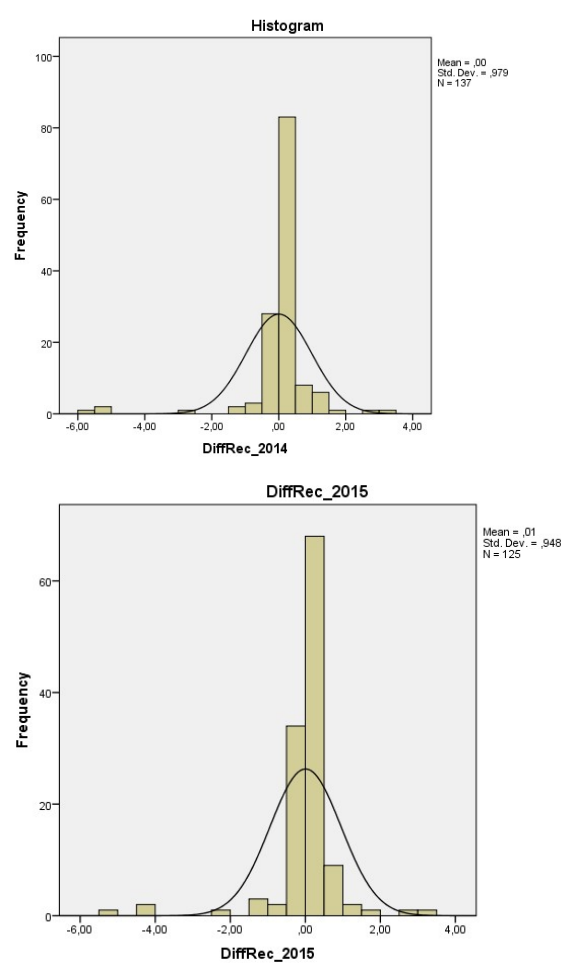
Table 9 Means and Standard Deviations with and without the outlier countries

\begin{tabular}{|r|c|c|c|c|c|c|c|}
\hline Together with outliers & $\mathrm{N}$ & Minimum & Maximum & Mean & Std. Dev & Skewness & Kurtosis \\
\hline DiffArriv_2014 & 151 & -16.47 & 7.15 & .0115 & 2.0858 & -4.786 & 38.529 \\
DiffArriv_2015 & 155 & -16.59 & 7.12 & -.0001 & 2.0795 & -4.984 & 40.505 \\
DiffRec_2014 & 137 & -5.63 & 3.12 & .0033 & .9792 & -3.312 & 19.332 \\
DiffRec_2015 & 125 & -5.47 & 3.31 & .0065 & .9481 & -2.811 & 16.850 \\
CDI & 155 & .000 & .733 & .3047 & .2105 & .186 & -1.184 \\
EFIA & 155 & .0000 & .9302 & .4593 & .2560 & -.081 & -1.189 \\
LDI & 155 & .000 & .988 & .4612 & .3007 & .050 & -1.295 \\
RFA & 155 & .0023 & .8603 & .4377 & .2314 & -.183 & -1.081 \\
RFIPew & 155 & .0020 & .7920 & .2926 & .1940 & .289 & -.960 \\
\hline Without outliers & $\mathrm{N}$ & Minimum & Maximum & Mean & Std. Dev & Skewness & Kurtosis \\
\hline DiffArriv_2014 & 148 & -2.59 & 7.15 & .2189 & 1.1251 & 2.493 & 13.462 \\
DiffArriv_2015 & 152 & -2.59 & 7.12 & .2062 & 1.0978 & 2.581 & 14.318 \\
DiffRec_2014 & 134 & -5.07 & 3.12 & .0928 & .7165 & -2.185 & 24.060 \\
DiffRec_2015 & 122 & -4.49 & 3.31 & .0966 & .7032 & -1.384 & 19.682 \\
CDI & 152 & .000 & .733 & .3053 & .2088 & .173 & -1.176 \\
EFIA & 152 & .0000 & .9302 & .4646 & .2546 & -.099 & -1.186 \\
LDI & 152 & .000 & .988 & .4605 & .2993 & .054 & -1.291 \\
RFA & 152 & .0023 & .8603 & .4363 & .2326 & -.171 & -1.095 \\
RFIPew & 152 & .0020 & .7920 & .2883 & .1927 & .314 & -.927 \\
\hline
\end{tabular}

The means and standard deviations of the diversity indicators have only slightly changed after omitting the three outlier countries. The descriptive statistics for DiffArriv and DiffRec however, are considerably changed (Table 9).

Table 10 Correlations without the 3 outlier countries

\begin{tabular}{|c|c|c|c|c|c|c|c|}
\hline \multicolumn{2}{|c|}{ Spearman's rho } & CDI & EFIA & LDI & $\begin{array}{l}\text { Cult Div } \\
\text { Max }\end{array}$ & RFA & RFIPew \\
\hline \multirow{2}{*}{$\begin{array}{l}\text { DiffArriv_2014, } \\
\mathrm{N}=148\end{array}$} & Correlation Coefficient & $-.227^{* * *}$ & $-.474^{* * *}$ & $-.472^{* * *}$ & $-.386^{* * *}$ & -.032 & .116 \\
\hline & Sig. (2-tailed) & .006 & .000 & .000 & .000 & .700 & .159 \\
\hline \multirow{2}{*}{$\begin{array}{l}\text { DiffArriv_2015, } \\
\mathrm{N}=152\end{array}$} & Correlation Coefficient & $-.243^{* *}$ & $-.469^{* * *}$ & $-.481^{* * *}$ & $-.400^{* *}$ & -.021 & $.139^{\#}$ \\
\hline & Sig. (2-tailed) & .003 & .000 & .000 & .000 & .796 & .088 \\
\hline \multirow{2}{*}{$\begin{array}{l}\text { DiffRec_2014. } \\
\text { N=134 }\end{array}$} & Correlation Coefficient & -.120 & $-.302^{* * *}$ & $-.278^{* * *}$ & $-.175^{*}$ & -.031 & $.154^{\#}$ \\
\hline & Sig. (2-tailed) & .166 & .000 & .001 & .043 & .720 & .076 \\
\hline \multirow{2}{*}{$\begin{array}{l}\text { DiffRec_2015, } \\
N=122\end{array}$} & Correlation Coefficient & -.120 & $-.269^{* * *}$ & $-.249^{* *}$ & $-.164^{\#}$ & -.049 & .122 \\
\hline & Sig. (2-tailed) & .189 & .003 & .006 & .071 & .588 & .180 \\
\hline
\end{tabular}

For notation see Table 5

The overall bivariate significant correlations between the DiffArriv and DiffRec values on the one hand, and the diversity indicators on the other, are all negative, suggesting that diversity is detrimental to the performance of the countries in the international tourism sector (Table 10). Both the DiffArriv and the DiffRec values are negatively correlated to ethnic and linguistic diversity and also to the maximum sociocultural diversity variable, but they do not show any significant relationship to religious diversity at 5\% level. At $10 \%$ level a slight positive impact of RFIPew can also be noted.

However, as correlations are not too strong, the question arises, whether overall averages might hide more specific features and effects for subgroups or segments of countries. In other words: is there any difference in the diversity patterns between touristically more successful and less successful countries? 
Grouping the countries according to DiffArriv2015 - as this is the difference variable with the most valid cases in it - two groups are created:

1. Group 1 (GR1): DiffArriv2015 $\leq 0.0 \%$ (77 countries)

2. Group 2 (GR2): DiffArriv2015 >0.0\% (75 countries)

Comparing the DiffArriv and DiffRec variables by this grouping, the means considerably differ among groups for tourism performance, and also for the sociocultural diversity indices, but not for religious diversity (see Table 11 and Table 12 ). This means, that there is some definite difference in the sociocultural diversity patterns between touristically successful countries and less successful ones, but no such difference can be identified for religious diversity.

Table 11 Descriptive statistics for tourism performance and diversity for the two groups

\begin{tabular}{|c|c|c|c|c|c|c|c|}
\hline & & $\mathrm{N}$ & Mean & Std. Dev & Std. Error & Minimum & Maximum \\
\hline \multirow[t]{3}{*}{ DiffArriv_2014 } & $<=.00$ & 73 & -.3768 & .59808 & .07000 & -2.59 & .00 \\
\hline & $.01+$ & 75 & .7986 & 1.21488 & .14028 & .01 & 7.15 \\
\hline & Total & 148 & .2189 & 1.12510 & .09248 & -2.59 & 7.15 \\
\hline \multirow[t]{3}{*}{ DiffArriv_2015 } & $<=.00$ & 77 & -.3562 & .58015 & .06611 & -2.59 & .00 \\
\hline & $.01+$ & 75 & .7836 & 1.20274 & .13888 & .01 & 7.12 \\
\hline & Total & 152 & .2062 & 1.09783 & .08905 & -2.59 & 7.12 \\
\hline \multirow[t]{3}{*}{ DiffRec_2014 } & $<=.00$ & 60 & -.0697 & .37000 & .04777 & -2.60 & .52 \\
\hline & $.01+$ & 74 & .2245 & .88620 & 10302 & -5.07 & 3.12 \\
\hline & Total & 134 & .0928 & .71648 & .06189 & -5.07 & 3.12 \\
\hline \multirow[t]{3}{*}{ DiffRec_2015 } & $<=.00$ & 50 & -.0658 & .34789 & .04920 & -2.26 & .34 \\
\hline & $.01+$ & 72 & .2094 & .85312 & .10054 & -4.49 & 3.31 \\
\hline & Total & 122 & .0966 & .70323 & .06367 & -4.49 & 3.31 \\
\hline \multirow[t]{3}{*}{ CDI } & $<=.00$ & 77 & .3622 & .223866 & .025512 & .000 & .733 \\
\hline & $.01+$ & 75 & .2468 & .175135 & .020223 & .000 & .624 \\
\hline & Total & 152 & .3053 & .208820 & .016938 & .000 & .733 \\
\hline \multirow[t]{3}{*}{ EFIA } & $<=.00$ & 77 & .586448 & .2414747 & .0275186 & .0000 & .9302 \\
\hline & $.01+$ & 75 & .339417 & .2026574 & .0234009 & .0392 & .7517 \\
\hline & Total & 152 & .464558 & .2546165 & .0206521 & .0000 & .9302 \\
\hline \multirow[t]{3}{*}{ LDI2016 } & $<=.00$ & 77 & .59039 & .292936 & .033383 & .000 & .988 \\
\hline & $.01+$ & 75 & .32719 & .243211 & .028084 & .000 & .871 \\
\hline & Total & 152 & .46052 & .299347 & .024280 & .000 & .988 \\
\hline \multirow[t]{3}{*}{ RFA } & $<=.00$ & 77 & .422582 & .2418604 & .0275625 & .0023 & .8192 \\
\hline & $.01+$ & 75 & .450299 & .2234472 & .0258015 & .0035 & .8603 \\
\hline & Total & 152 & .436258 & .2326017 & .0188665 & .0023 & .8603 \\
\hline \multirow[t]{3}{*}{ RFIPew } & $<=.00$ & 77 & .261653 & .2013147 & .0229419 & .0040 & .7139 \\
\hline & $.01+$ & 75 & .315584 & .1807134 & .0208670 & .0020 & .7920 \\
\hline & Total & 152 & .288263 & .1927020 & .0156302 & .0020 & .7920 \\
\hline \multirow[t]{3}{*}{ Cult Div Max } & $<=.00$ & 77 & .6709 & .22680 & .02585 & .00 & .99 \\
\hline & $.01+$ & 75 & .4122 & .21326 & .02463 & .04 & .87 \\
\hline & Total & 152 & .5433 & .25500 & .02068 & .00 & .99 \\
\hline
\end{tabular}

The nonparametric Mann-Whitney U-test and the Wilcoxon-test also prove what the mean values suggested (Table 12). The significance test shows for CDI, EFIA, LDI, and CultDivMax, that the p-values are all less than 0.05 , therefore the median values of the 
sociocultural fragmentation values significantly differ between the two groups. Regarding religious diversity no such difference was found.

Table 12 Test of significant differences of group medians between two groups

\begin{tabular}{|l|r|r|r|r|r|r|r|}
\hline & \multicolumn{1}{|c|}{ CDI } & EFIA & LDI & RFA & RFIPew & \multicolumn{1}{c|}{ Max } & \multicolumn{1}{c|}{ Max } \\
\hline Mann-Whitney U & 2157.000 & 1372.500 & 1509.000 & 2858.000 & 2558.000 & 1256.000 & 2852.000 \\
Wilcoxon W & 5007.000 & 4222.500 & 4359.000 & 6098.000 & 5798.000 & 4106.000 & 6092.000 \\
Z & -3.019 & -5.827 & -5.339 & -.508 & -1.583 & -6.245 & -.530 \\
Asymp. Sig. & .003 & .000 & .000 & .611 & .114 & .000 & .596 \\
(2-tailed) & & & .00 & & & .000 \\
\hline
\end{tabular}

Figure 2 Group means for tourism importance and for diversity indicators
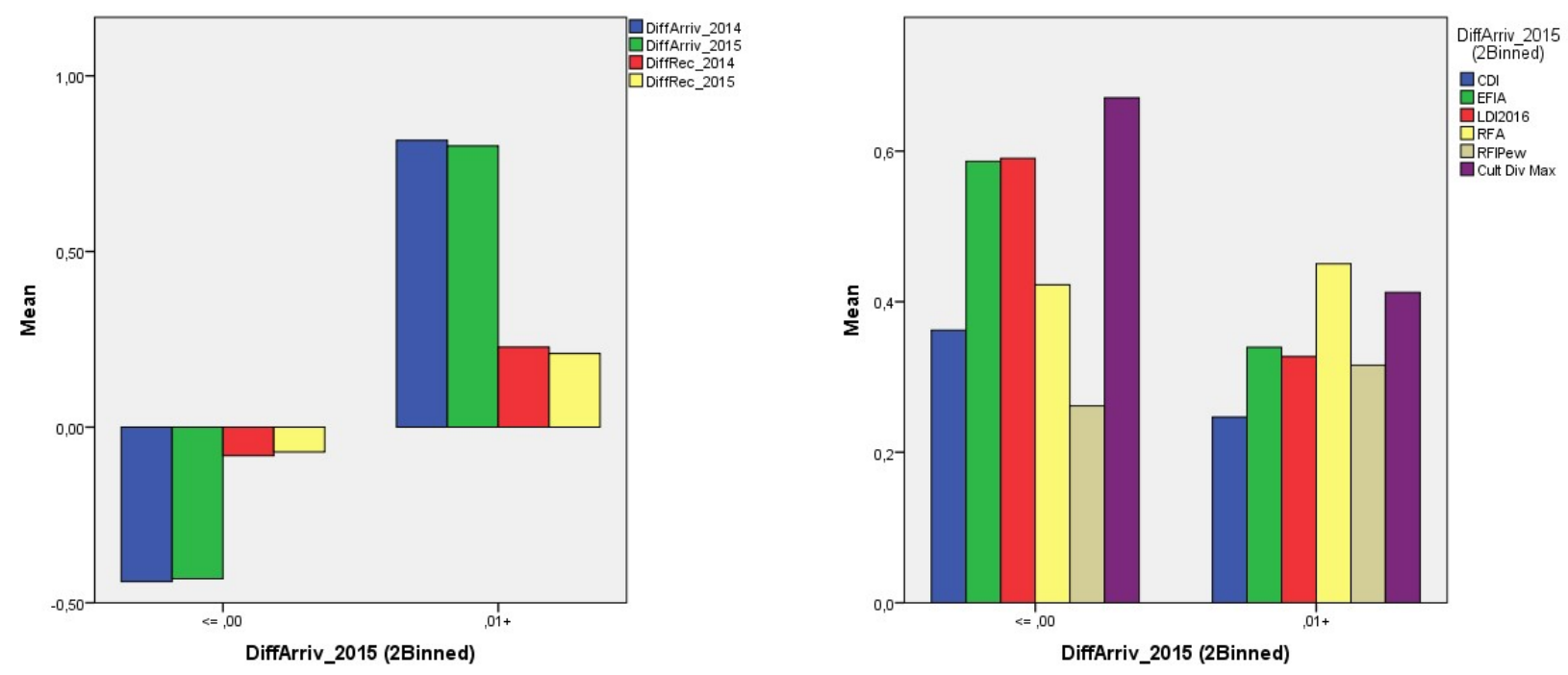

Another interesting feature of the present grouping is, that while the second group shows higher mean values for DiffArriv and DiffRec for both years, this is not true for all the diversity measures. The mean values for CDI, EFIA, LDI and CultDivMax are all higher in Group 2, but not for RFA and RFIPew. For religious diversity the lower mean values are in Group 1, where DiffArriv and Diff Rec values are negative; the higher religious diversity mean values are associated with Group2, where all DiffArriv and DiffRec values have a positive mean value (Figure 2).

Looking at the distributions of the diversity indicators in the two groups (Figure 3), the EFIA, LDI and CultDivMax sociocultural diversity values tend to accumulate in the higher value ranges for the first group and in the lower value ranges in the second group. However, this is quite opposite in the case of the religious diversity index RFIPew. Its values tend to be more in the lower range for the first group and more in the medium-high range for the second group. This figure underlines the conclusions driven from the group means. The countries, which perform worse in world tourism, tend to have higher sociocultural diversity, but lower 
religious diversity, but countries with better tourism performance tend to have lower sociocultural diversity values and higher religious diversity.

Figure 3 Distributions of diversity measures according to the three groups
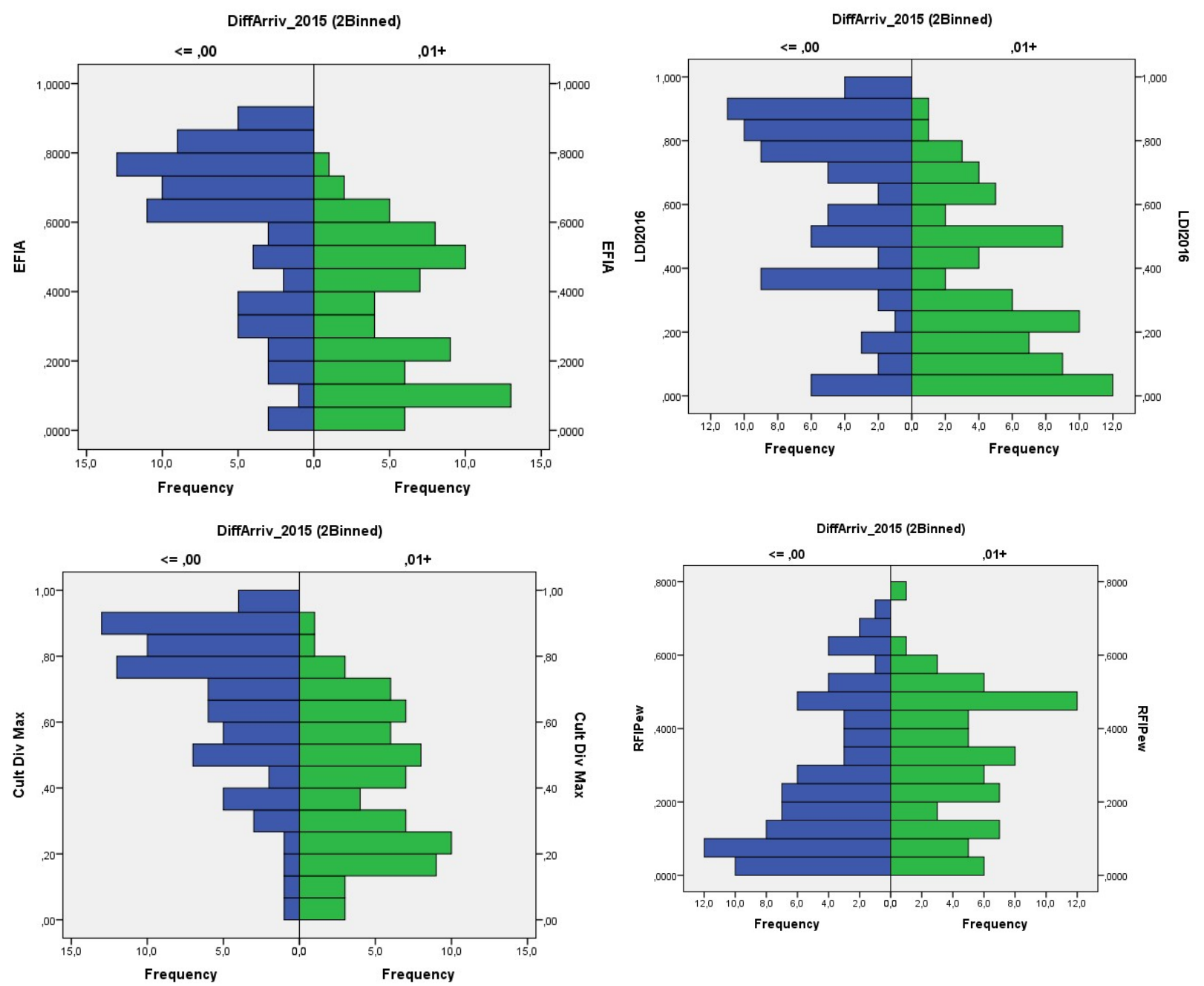

Another interesting feature of Figure 3 is the shape of the distributions for the two country groups. The distributions seem to be quite opposite for Group1 and Group2 countries. While EFIA, LDI and CultDivMax have the highest frequencies at higher diversity values for Group1 countries, in Group2 their highest peaks tend to occur at low diversity figures although the distribution is seemingly multimodal, having a second peak at medium diversity levels. However, in the case of RFIPew the peak in Group 1 occurs at low religious diversity with a second peak at medium diversity, and for Group 2 the peak is at high diversity, while medium to low diversity values are also quite frequent. This means that countries who perform better in world tourism tend to have higher religious diversity, and low or medium sociocultural diversity - though many of them still can be quite heterogeneous in religion. 
Countries which are poorer performers in world tourism often have low religious diversity and high sociocultural diversity values.

\section{DISCUSSION AND CONCLUSIONS}

The analysis has shown that the ethnic, linguistic fractionalisation, and the maximum sociocultural fractionalisation have a significant impact on the Travel and Tourism Competitiveness Index of countries, i.e., their degree of competitiveness in the international tourism sector. The impact of these sociocultural variables is similar on tourism arrivals and tourism receipts measured as $\%$ of the world total value. On the contrary to that, religious diversity did not have any significant impact on tourism competitiveness, arrivals and receipts.

The explanation for the negative impact of ethnicity and language diversity may be, that diversity may hamper the nations' ability to achieve nation-wide development projects, i.e. development of the transportation infrastructures, or of other public infrastructural networks, but the existence of good quality infrastructure is obviously necessary for better tourism performance. Therefore greater diversity leads to less development in related areas. Contrary to the findings by earlier research (Das \& DiRienzo, 2009), no evidence was found for the mitigating effects of higher levels of GDP per capita. This may be due to several factors. Das and DiRienzo analysed tourism competitiveness data for 2007, while diversity data were derived from 1985. This is a 22 year lag, during which the original ethnically diverse population could be nicely integrated into affluent societies, where income levels allowed for efficient intergration strategies. Our ethnic diversity data were derived from the year 2001, and tourism competitive indices were for 2015 and 2017 - i.e. a 14-16 year lag. However, this period contained the 2008-2009 world crisis, and the migration crises of the recent years, which changed the financial and social resources to build on the beneficial impacts of intergration.

Generally no definite impact of religious diversity was found. However, splitting the countries into two groups (poor performers and good performers) religiouos diversity tended to be higher among good performers and lower among poor performers. This is similar to the earlier findings by Bacsi (2017a), in which the author also found evidence for the beneficial impacts of high religious diversity on the level of per capita GNI, and on the human development index. 
As the analysis of the country grouping revealed, both ethnic, linguistic, and religious diversity distributions seem to follow a bimodal distribution in the group of touristically more successful countries. This may suggest to the possibility, that this groups contains two segments with two different distributions, one with a peak at low diversity levels, and another at medium to high diversity levels. This means, that there may be countries for which high tourism performance goes together with high diversity, while for others top tourism performance occurs with mainly low diversity values. To reveal typical features of these segments is the issue of further research.

\section{REFERENCES}

Adler, N.J., \& Gundersen, A. (2008). International Dimensions of Organizational Behavior. Thomson- South Western. Mason - USA

Alesina, A., Devleeschauwer, A., Easterly, W., Kurlat. S., \& Wacziarg, R. (2003). Fractionalization. Journal of Economic Growth. 8(2), 155-94.

Alesina, A., \& La Ferrara, E. (2005). Ethnic Diversity and Economic Performance. Journal of Economic Literature. Vol 42 (Sept 2005): 762-822.

Alesina, A., Harnoss, J., \& Rapoport, H. (2016a). Birthplace diversity and economic prosperity. Journal of Economic Growth. 21(2), 101-138. https://doi.org/10.1007/ s10887-016-9127-6

Alesina, A., Michalopoulos. S., \& Papaioannou, E. (2016b). Ethnic inequality. Journal of Political Economy. 124(2). 428-488. https://doi.org/10.1086/685300

Bacsi, Zs. (2017a). Does Diversity Hinder Development? Evidence for Ethnic Diversity and GNI in 155 Countries. In: Farkas Attila (Filozófia). F. Orosz Sára. Rudnák Ildikó (szerk.. 2017). Tudományterületek a multikulturalitás kontextusában. Branches of Sciences in Multicultural Context. Gödöllö: Szent István Egyetemi Kiadó. pp. 5-20.

Bacsi, Zs. (2017b). Megosztottság és sokféleség - a kulturális heterogenitás viszonya az életminőséghez és fejlettséghez. (Division and diversity -the relations to cultural heterogeneity to quality of life and development. In Hungarian). Közgazdasági Szemle. Vol. LXIV. No 7-8. p738-773.

Barnett, G.A., \& Kincaid D.L. (1983). Cultural convergence: a mathematical theory. In: Gudykunst W (ed). International Intercultural Communication Annual VII. Beverly Hills: Sage. pp. 171-94.

Blum, S. (2007). In pursuit of authenticity: Authorship. Food. Ethnic Tourism/Heritage. and Historic Preservation.Keynote address on 16-18 Oct 2007 at 'Revitalization and Preservation of Old Architecture and the Sustainable Development of Rural Taiwan'. National Pingtung Univ of Science and Technology. Taiwan. Proceedings. p.117-129.

Burger-Menzel, B., \& Syring, N. (2013). Managing Across Cultures: How to Positively Impact Innovation through Diversity. Cross-Cultural Conference 2013. 8th May. University of Applied Sciences Upper Austria School of Management. Steyr. Proceedings p. 17-26.

CIA World Factbook (2017). https://www.cia.gov/library/publications/resources/the-worldfactbook/ Accessed: 10 May 2017.

Collier, P. (2000). Ethnicity. Politics. and Economic Performance. Economics and Politics. $12(3), 225-45$. 
Collier, P., \& Gunning, J. W. (1999). Explaining African Economic Performance. Journal of Economic Literature. 37(1), 64-111.

Collin, J., \& Kunz, P. (2007). Ethnic entrepreneurs. ethnic precincts and tourism: the case of Sydney. Australia. In: Richards -Wilson (eds. 2007). p 201-215.

Csapó, J., \& Matesz, K. (2007). A kulturális turizmus jelentősége és szerepe napjaink idegenforgalmában. (The importance and role of cultural tourism in contemporary tourism (In Hungarian)). Földrajzi Értesítő. LVI.évf. .3-4. p.291-301.

Das, J. ,\& DiRienzo, C. (2010). Tourism Competitiveness and the Role of Diversity: A CrossCountry Analysis.Proceedings of 'Latest trends on Cultural Heritage and Tourism'. 3rd WSEAS International Conference on Cultural Heritage and Tourism (CUHT'10). Corfu Island. Greece. July 22-24. 2010. p 19-27.

DeCoster, J. (2006). Testing Group Differences using T-tests, ANOVA, and Nonparametric Measures. Retrieved 3rd Aug 2017 from http://www.stathelp.com/notes.html

Doorne, S., Ateljevic, I., \& Bai, Z. (2003). Representing Identities Through Tourism: Encounters of Ethnic Minorities in Dali. Yunnan Province. People's Republic of China. International Journal of Tourism Research. 5. p. 1-11.

Easterly, W., \& Levine, R. (1997). Africa's Growth Tragedy: Policies and Ethnic Divisions. Quarterly Journal of Economics. 112(4), 1203-50.

Ethnologue (2016). Ethnologue 19th edition - -(Table). accessed: April 2016

Fearon, J. D. ( 2003). Ethnic and Cultural Diversity by Country. Journal of Economic Growth. $8(2), 195-222$.

Fourie, J., Rosselló, J., \& Santana-Gallego, M. (2015). Religion, Religious Diversity and Tourism. Kyklos, 68: 51-64. doi:10.1111/kykl.12066

Florida. R. (2005). Cities and the creative class. New York: Routledge.

Gébert, J., Bajmóczy, Z., \& Málovics. Gy. (2017). How to Evaluate Local Economic Development Projects from a People-Centered Perspective? An Analytical Framework Based on the Capability Approach. Deturope. 9(2) (forthcoming).

Greenberg, J. H. (1956). The Measurement of Linguistic Diversity Language 32 (1), 109-115. https://dx.doi.org/10.2307\%2F410659

Harmon, D., \& Loh. J. (2010). The Index of Linguistic Diversity: A New Quantitative Measure of Trends in the Status of the World's Languages. Language Documentation and Conservation. 4, 97-151.

Hoffmann, L. (2003). The Marketing of Diversity in the Inner City: Tourism and Regulation in Harlem. International Journal of Urban and Regional Research. Vol. 27(2), 286-299.

La Porta, R., Lopez-de-Silanes, F., Shleifer, A., \& Vishny, R. (1999). The Quality of Government. Journal of Law. Economics. and Organization.15(1): 222-79.

Landry, C. (2000). The Creative City: A Toolkit for Urban Innovators. Earthscan, London.

Landry, C., \& Bianchini. F. (1995). The Creative City. London: Demos.

Lin, J. (2008). Los Angeles Chinatown: Tourism. Gentrification. and the Rise of an Ethnic Growth Machine.. Amerasian Journal. 34(3), 110-126

McCannell, D. (1992). Empty meeting grounds - The tourist papers. Chapter 7 Reconstructed Ethnicity. p. 158- 171. Routledge. London-New York

Nate-Chei, A. (2009). Ethnic Tourism as a Space of Understanding „The Other”: Exploring the Case of White Tai Ethnic Tourist Villages in Upland Vietnam. Paper presented in the Third International Conference on Southeast Asia (ICONSEA 2009) . 8th - 9th Dec 2009. Faculty of Arts and Social Sciences. University of Malaya. Kuala Lumpur.

Nisnevich, A. (2013). Quantifying Linguistic Diversity. Retrieved from http://alex.nisnevich.com/blog/2013/01/11/quantifying_linguistic_diversity.html. Accessed: April 2016 
PEW Research Centre (2012). The Global Religious Landscape: A Report on the Size and Distribution of the World's Major Religious Groups as of 2010. http://www.pewforum.org/files/2014/01/global-religion-full.pdf. Accessed 9 October 2013

Putnam, R. D. (2007). E Pluribus Unum: Diversity and Community in the Twenty-first Century. The 2006 Johan Skytte Prize Lecture. Scandinavian Political Studies. Vol. 30(2), 137-174.

Richards, G., \& Wilson, J. (eds) (2007). Tourism. Creativity and Development. Routledge. Taylor and Francis Group. London - New York.

Rovinaru, M., \& Rovinaru, F. (2010). Managing Cultural Diversity in International Tourism. Revista Economica. Nr 3 (50), 429-434

Ságvári, B., \& Dessewffy, T. (2006). A kreatív gazdaságról. - Európa és Magyarország a kreatív korban. (About Creative Economy - Europe and Hungary in the Creative Age In Hungarian). Demos Könyvek. Budapest

Sharpley, R. (1996). Tourism and Consumer Culture in Postmodern Society. In: Tourism and Culture Towards the 21st Century Cultural Change. Robinson. M. - Evans. N. Callagha. P. (eds). Conference Proceedings. The Centre for Travel and Tourism. Sunderland.

Shaw, S. (2007). Ethnic quarters in the cosmopolitan-creative city In: Richards -Wilson (eds.. 2007).p 189-200

Siew, I. N., Lee, J. A., \& Soutar, G. N. (2007). Tourists' intention to visit a country: The impact of cultural distance, Tourism Management, 28(6), 1497-1506

Sparber, C. (2007). Racial Diversity and Macroeconomic Productivity across US States and Cities. Working Paper. Colgate-University. Retrieved from https://www.colgate.edu/portaldata/imagegallerywww/0225a1d8-0850-4bb1-88f2fc550662e306/ImageGallery/macro.pdf

Steele, J. (2008). Population Structure and Diversity Indices. In: S. Matsumura. P. Forster \& C. Renfrew (eds). Simulations. Genetics and Human Prehistory. McDonald Institute for Archaeological Research. Chapter 18: 187-191.

UNDP (2010). Human Development Report 2010 -The Real Wealth of Nations: Pathways to Human Development. UNDP.

UNDP (2015). Human Development Report 2015 - Work for Human Development. HDI values (Table 2). International mobility 2013 (Table 15). UNDP

UNESA (2017). World Population Prospects: The 2017 Revision. United Nations. Department of Economic and Social Affairs. Population Division .

Urry, J. (1990). The Tourist Gaze: Leisure and Travel in Contemporary Societies. London: Sage

VanAlstine, J., Cox. S. R., \& Roden. D. M. (2013). The Costs and Benefits of Diversity: Are Religious Differences Most Important? Journal of Global Business Issues. 7(2). 9-20.

Vollmer. A., \& Wolf. P. (2015). Adaption of conflict management styles during the encounter of cultures: Findings from a Russian-West European case study. International Journal of Cross Cultural Management. Vol. 15(2), 151-166

WEF (2015. 2017). The Travel \& Tourism Competitiveness Index Dataset 2015/2017. World Economic Forum. Geneva.

Yencken, D. (1988). The Creative City. Meanjin. 47(4), Summer 1988: 597-608. Retrieved from

http://search.informit.com.au/documentSummary;dn=582212487737872;res=IELLCC 
APPENDIX

List of countries according to the groups based on DiffArriv2014 (Outliers: China. India. Japan)

\begin{tabular}{|c|c|c|c|c|c|c|c|c|c|c|}
\hline$G R$ & No & $\begin{array}{c}\text { Casecod } \\
e\end{array}$ & Country & $\begin{array}{c}\text { DiffArri } \\
\text { v_2015 }\end{array}$ & $C D I$ & EFIA & $L D I$ & $R F A$ & $\begin{array}{c}\text { RFIPe } \\
\quad w\end{array}$ & $\begin{array}{l}\text { Cult } \\
\text { Div } \\
\text { Max }\end{array}$ \\
\hline 1 & 1 & 48 & Indonesia & -2.590 & 0.522 & 0.735 & 0.816 & 0.234 & 0.230 & 0.820 \\
\hline 1 & 2 & 71 & Pakistan & -2.530 & 0.289 & 0.710 & 0.755 & 0.385 & 0.070 & 0.760 \\
\hline 1 & 3 & 31 & Nigeria & -2.310 & 0.660 & 0.851 & 0.891 & 0.742 & 0.519 & 0.890 \\
\hline 1 & 4 & 128 & Brazil & -2.220 & 0.020 & 0.541 & 0.099 & 0.605 & 0.203 & 0.540 \\
\hline 1 & 5 & 67 & Bangladesh & -2.160 & 0.141 & 0.045 & 0.395 & 0.209 & 0.185 & 0.400 \\
\hline 1 & 6 & 13 & Ethiopia & -1.140 & 0.562 & 0.724 & 0.862 & 0.625 & 0.485 & 0.860 \\
\hline 1 & 7 & 59 & Philippines & -1.020 & 0.116 & 0.239 & 0.842 & 0.306 & 0.155 & 0.840 \\
\hline 1 & 8 & 10 & Dem Repc of Congo & -0.960 & 0.628 & 0.875 & 0.948 & 0.702 & 0.082 & 0.950 \\
\hline 1 & 9 & 66 & Vietnam & -0.620 & 0.210 & 0.238 & 0.267 & 0.508 & 0.642 & 0.270 \\
\hline 1 & 10 & 76 & Iran & -0.600 & 0.542 & 0.668 & 0.642 & 0.115 & 0.010 & 0.670 \\
\hline 1 & 11 & 38 & Tanzania & -0.550 & 0.564 & 0.735 & 0.871 & 0.633 & 0.499 & 0.870 \\
\hline 1 & 12 & 20 & Kenya & -0.470 & 0.601 & 0.859 & 0.927 & 0.777 & 0.270 & 0.930 \\
\hline 1 & 13 & 140 & Iraq & -0.460 & 0.355 & 0.369 & 0.761 & 0.484 & 0.020 & 0.760 \\
\hline 1 & 14 & 73 & Afghanistan & -0.460 & 0.679 & 0.769 & 0.790 & 0.272 & 0.006 & 0.790 \\
\hline 1 & 15 & 130 & Colombia & -0.430 & 0.020 & 0.601 & 0.019 & 0.148 & 0.140 & 0.600 \\
\hline 1 & 16 & 154 & Sudan (-2011) & -0.420 & 0.698 & 0.715 & 0.362 & 0.431 & 0.174 & 0.710 \\
\hline 1 & 17 & 65 & Uzbekistan & -0.400 & 0.442 & 0.413 & 0.476 & 0.213 & 0.064 & 0.480 \\
\hline 1 & 18 & 44 & Myanmar & -0.400 & 0.419 & 0.506 & 0.522 & 0.197 & 0.347 & 0.520 \\
\hline 1 & 19 & 40 & Uganda & -0.370 & 0.647 & 0.930 & 0.927 & 0.633 & 0.235 & 0.930 \\
\hline 1 & 20 & 70 & Nepal & -0.360 & 0.542 & 0.663 & 0.754 & 0.142 & 0.335 & 0.750 \\
\hline 1 & 21 & 52 & Korea, North & -0.350 & 0.002 & 0.002 & 0.000 & 0.660 & 0.459 & 0.000 \\
\hline 1 & 22 & 61 & Taiwan & -0.340 & 0.169 & 0.274 & 0.489 & 0.685 & 0.714 & 0.490 \\
\hline 1 & 23 & 136 & Venezuela & -0.340 & 0.020 & 0.497 & 0.040 & 0.135 & 0.193 & 0.500 \\
\hline 1 & 24 & 150 & Algeria & -0.300 & 0.000 & 0.339 & 0.360 & 0.009 & 0.041 & 0.360 \\
\hline 1 & 25 & 147 & Syria & -0.300 & 0.235 & 0.540 & 0.360 & 0.431 & 0.136 & 0.540 \\
\hline 1 & 26 & 16 & Ghana & -0.280 & 0.388 & 0.673 & 0.858 & 0.799 & 0.410 & 0.860 \\
\hline 1 & 27 & 23 & Madagascar & -0.280 & 0.192 & 0.879 & 0.789 & 0.519 & 0.265 & 0.880 \\
\hline 1 & 28 & 151 & Egypt & -0.260 & 0.000 & 0.184 & 0.503 & 0.198 & 0.097 & 0.500 \\
\hline 1 & 29 & 149 & Yemen & -0.250 & 0.078 & 0.000 & 0.581 & 0.002 & 0.018 & 0.580 \\
\hline 1 & 30 & 19 & Ivory Coast & -0.240 & 0.557 & 0.820 & 0.900 & 0.755 & 0.648 & 0.900 \\
\hline 1 & 31 & 4 & Burkina Faso & -0.220 & 0.354 & 0.738 & 0.721 & 0.580 & 0.546 & 0.740 \\
\hline 1 & 32 & 1 & Angola & -0.220 & 0.242 & 0.787 & 0.770 & 0.628 & 0.177 & 0.790 \\
\hline 1 & 33 & 30 & Niger & -0.210 & 0.600 & 0.652 & 0.578 & 0.201 & 0.032 & 0.650 \\
\hline 1 & 34 & 25 & Mali & -0.210 & 0.590 & 0.691 & 0.867 & 0.182 & 0.144 & 0.870 \\
\hline 1 & 35 & 6 & Cameroon & -0.210 & 0.733 & 0.864 & 0.974 & 0.734 & 0.468 & 0.970 \\
\hline 1 & 36 & 28 & Mozambique & -0.180 & 0.285 & 0.693 & 0.921 & 0.676 & 0.609 & 0.920 \\
\hline 1 & 37 & 72 & Sri Lanka & -0.160 & 0.386 & 0.415 & 0.446 & 0.485 & 0.486 & 0.450 \\
\hline 1 & 38 & 8 & Chad & -0.150 & 0.727 & 0.862 & 0.933 & 0.641 & 0.529 & 0.930 \\
\hline
\end{tabular}




\begin{tabular}{|c|c|c|c|c|c|c|c|c|c|c|}
\hline 1 & 39 & 24 & Malawi & -0.140 & 0.294 & 0.674 & 0.692 & 0.819 & 0.298 & 0.690 \\
\hline 1 & 40 & 17 & Guinea & -0.140 & 0.490 & 0.739 & 0.748 & 0.265 & 0.275 & 0.750 \\
\hline 1 & 41 & 35 & Somalia & -0.140 & 0.290 & 0.812 & 0.363 & 0.003 & 0.004 & 0.810 \\
\hline 1 & 42 & 90 & Belarus & -0.130 & 0.228 & 0.322 & 0.411 & 0.612 & 0.411 & 0.410 \\
\hline 1 & 43 & 134 & Peru & -0.120 & 0.506 & 0.657 & 0.339 & 0.199 & 0.149 & 0.660 \\
\hline 1 & 44 & 148 & United Arab Emirates & -0.110 & 0.650 & 0.625 & 0.707 & 0.331 & 0.388 & 0.710 \\
\hline 1 & 45 & 2 & Benin & -0.110 & 0.400 & 0.787 & 0.933 & 0.554 & 0.627 & 0.930 \\
\hline 1 & 46 & 116 & Haiti & -0.100 & 0.000 & 0.095 & 0.000 & 0.470 & 0.233 & 0.100 \\
\hline 1 & 47 & 5 & Burundi & -0.100 & 0.040 & 0.295 & 0.002 & 0.516 & 0.159 & 0.300 \\
\hline 1 & 48 & 41 & Zambia & -0.100 & 0.189 & 0.781 & 0.830 & 0.736 & 0.047 & 0.830 \\
\hline 1 & 49 & 33 & Senegal & -0.090 & 0.402 & 0.694 & 0.778 & 0.150 & 0.069 & 0.780 \\
\hline 1 & 50 & 152 & Libya & -0.090 & 0.127 & 0.792 & 0.557 & 0.057 & 0.066 & 0.790 \\
\hline 1 & 51 & 62 & Tajikistan & -0.080 & 0.492 & 0.511 & 0.276 & 0.339 & 0.064 & 0.510 \\
\hline 1 & 52 & 12 & Eritrea & -0.080 & 0.398 & 0.652 & 0.672 & 0.425 & 0.470 & 0.670 \\
\hline 1 & 53 & 34 & Sierra Leone & -0.080 & 0.534 & 0.819 & 0.842 & 0.540 & 0.348 & 0.840 \\
\hline 1 & 54 & 58 & Papua New Guinea & -0.080 & 0.000 & 0.272 & 0.988 & 0.552 & 0.016 & 0.990 \\
\hline 1 & 55 & 32 & Rwanda & -0.070 & 0.000 & 0.324 & 0.091 & 0.507 & 0.126 & 0.320 \\
\hline 1 & 56 & 64 & Turkmenistan & -0.070 & 0.328 & 0.392 & 0.385 & 0.233 & 0.131 & 0.390 \\
\hline 1 & 57 & 131 & Ecuador & -0.060 & 0.480 & 0.655 & 0.182 & 0.142 & 0.112 & 0.660 \\
\hline 1 & 58 & 127 & Bolivia & -0.060 & 0.662 & 0.740 & 0.565 & 0.209 & 0.116 & 0.740 \\
\hline 1 & 59 & 22 & Liberia & -0.060 & 0.644 & 0.908 & 0.898 & 0.488 & 0.248 & 0.910 \\
\hline 1 & 60 & 39 & Togo & -0.060 & 0.602 & 0.710 & 0.905 & 0.660 & 0.659 & 0.910 \\
\hline 1 & 61 & 26 & Mauritania & -0.050 & 0.272 & 0.615 & 0.228 & 0.015 & 0.018 & 0.620 \\
\hline 1 & 62 & 7 & Cent African Rep & -0.050 & 0.511 & 0.830 & 0.959 & 0.792 & 0.192 & 0.960 \\
\hline 1 & 63 & 121 & Guatemala & -0.040 & 0.493 & 0.512 & 0.517 & 0.375 & 0.092 & 0.520 \\
\hline 1 & 64 & 104 & Moldova & -0.040 & 0.401 & 0.554 & 0.389 & 0.560 & 0.051 & 0.550 \\
\hline 1 & 65 & 143 & Kuwait & -0.040 & 0.540 & 0.660 & 0.605 & 0.675 & 0.423 & 0.660 \\
\hline 1 & 66 & 122 & Honduras & -0.030 & 0.167 & 0.187 & 0.039 & 0.236 & 0.221 & 0.190 \\
\hline 1 & 67 & 133 & Paraguay & -0.030 & 0.039 & 0.169 & 0.386 & 0.212 & 0.061 & 0.390 \\
\hline 1 & 68 & 9 & Congo & -0.030 & 0.562 & 0.875 & 0.810 & 0.664 & 0.253 & 0.870 \\
\hline 1 & 69 & 126 & Argentina & -0.020 & 0.000 & 0.255 & 0.165 & 0.224 & 0.259 & 0.260 \\
\hline 1 & 70 & 14 & Gabon & -0.020 & 0.382 & 0.769 & 0.846 & 0.667 & 0.395 & 0.850 \\
\hline 1 & 71 & 18 & Guinea-Bissau & -0.020 & 0.568 & 0.808 & 0.859 & 0.613 & 0.661 & 0.860 \\
\hline 1 & 72 & 15 & Gambia & -0.010 & 0.548 & 0.786 & 0.776 & 0.097 & 0.094 & 0.790 \\
\hline 1 & 73 & 11 & Djibouti & -0.010 & 0.404 & 0.796 & 0.473 & 0.044 & 0.061 & 0.800 \\
\hline 1 & 74 & 56 & Mongolia & 0.000 & 0.227 & 0.368 & 0.172 & 0.080 & 0.565 & 0.370 \\
\hline 1 & 75 & 42 & Zimbabwe & 0.000 & 0.141 & 0.387 & 0.534 & 0.736 & 0.235 & 0.530 \\
\hline 1 & 76 & 99 & $\begin{array}{ll}\text { Bosnia } & \text { and } \\
\text { Herzegovina } & \end{array}$ & 0.000 & 0.146 & 0.630 & 0.694 & 0.685 & 0.522 & 0.690 \\
\hline 1 & 77 & 68 & Bhutan & 0.000 & 0.518 & 0.605 & 0.828 & 0.379 & 0.391 & 0.830 \\
\hline 2 & 1 & 103 & Macedonia & 0.010 & 0.432 & 0.502 & 0.487 & 0.590 & 0.494 & 0.500 \\
\hline 2 & 2 & 132 & Guyana & 0.010 & 0.460 & 0.620 & 0.514 & 0.788 & 0.498 & 0.620 \\
\hline 2 & 3 & 118 & Trinidad and Tobago & 0.020 & 0.380 & 0.648 & 0.597 & 0.794 & 0.510 & 0.650 \\
\hline 2 & 4 & 120 & El Salvador & 0.040 & 0.180 & 0.198 & 0.000 & 0.356 & 0.210 & 0.200 \\
\hline 2 & 5 & 124 & Nicaragua & 0.040 & 0.095 & 0.484 & 0.052 & 0.429 & 0.248 & 0.480 \\
\hline
\end{tabular}




\begin{tabular}{|c|c|c|c|c|c|c|c|c|c|c|}
\hline 2 & 6 & 47 & Fiji & 0.050 & 0.553 & 0.548 & 0.608 & 0.568 & 0.503 & 0.610 \\
\hline 2 & 7 & 87 & Slovakia & 0.060 & 0.293 & 0.254 & 0.247 & 0.566 & 0.252 & 0.290 \\
\hline 2 & 8 & 74 & Armenia & 0.070 & 0.124 & 0.127 & 0.140 & 0.458 & 0.030 & 0.140 \\
\hline 2 & 9 & 75 & Azerbaijan & 0.070 & 0.187 & 0.205 & 0.197 & 0.490 & 0.060 & 0.200 \\
\hline 2 & 10 & 144 & Lebanon & 0.070 & 0.195 & 0.131 & 0.198 & 0.789 & 0.478 & 0.200 \\
\hline 2 & 11 & 37 & Swaziland & 0.070 & 0.143 & 0.058 & 0.209 & 0.444 & 0.214 & 0.210 \\
\hline 2 & 12 & 21 & Lesotho & 0.070 & 0.057 & 0.255 & 0.260 & 0.721 & 0.062 & 0.260 \\
\hline 2 & 13 & 27 & Mauritius & 0.080 & 0.448 & 0.463 & 0.216 & 0.639 & 0.590 & 0.460 \\
\hline 2 & 14 & 29 & Namibia & 0.090 & 0.589 & 0.633 & 0.818 & 0.663 & 0.049 & 0.820 \\
\hline 2 & 15 & 129 & Chile & 0.100 & 0.167 & 0.186 & 0.040 & 0.384 & 0.193 & 0.190 \\
\hline 2 & 16 & 145 & Oman & 0.110 & 0.404 & 0.437 & 0.702 & 0.432 & 0.255 & 0.700 \\
\hline 2 & 17 & 125 & Panama & 0.120 & 0.168 & 0.553 & 0.287 & 0.334 & 0.133 & 0.550 \\
\hline 2 & 18 & 114 & Cuba & 0.120 & 0.020 & 0.591 & 0.001 & 0.506 & 0.566 & 0.590 \\
\hline 2 & 19 & 84 & Latvia & 0.140 & 0.441 & 0.587 & 0.531 & 0.556 & 0.497 & 0.590 \\
\hline 2 & 20 & 85 & Lithuania & 0.150 & 0.259 & 0.322 & 0.404 & 0.414 & 0.184 & 0.400 \\
\hline 2 & 21 & 117 & Jamaica & 0.160 & 0.027 & 0.413 & 0.017 & 0.616 & 0.372 & 0.410 \\
\hline 2 & 22 & 3 & Botswana & 0.160 & 0.161 & 0.410 & 0.441 & 0.599 & 0.434 & 0.440 \\
\hline 2 & 23 & 119 & Costa Rica & 0.170 & 0.078 & 0.237 & 0.036 & 0.241 & 0.167 & 0.240 \\
\hline 2 & 24 & 141 & Israel & 0.170 & 0.246 & 0.344 & 0.718 & 0.347 & 0.393 & 0.720 \\
\hline 2 & 25 & 92 & Finland & 0.180 & 0.132 & 0.132 & 0.171 & 0.253 & 0.303 & 0.170 \\
\hline 2 & 26 & 36 & South Africa & 0.190 & 0.530 & 0.752 & 0.871 & 0.860 & 0.318 & 0.870 \\
\hline 2 & 27 & 88 & Slovenia & 0.200 & 0.170 & 0.222 & 0.167 & 0.287 & 0.352 & 0.220 \\
\hline 2 & 28 & 57 & New Zealand & 0.200 & 0.363 & 0.397 & 0.291 & 0.811 & 0.540 & 0.400 \\
\hline 2 & 29 & 50 & Kazakhstan & 0.200 & 0.620 & 0.617 & 0.514 & 0.590 & 0.441 & 0.620 \\
\hline 2 & 30 & 53 & Kyrgyzstan & 0.200 & 0.624 & 0.675 & 0.463 & 0.447 & 0.213 & 0.680 \\
\hline 2 & 31 & 135 & Uruguay & 0.210 & 0.000 & 0.250 & 0.089 & 0.355 & 0.499 & 0.250 \\
\hline 2 & 32 & 54 & Laos & 0.210 & 0.020 & 0.514 & 0.691 & 0.545 & 0.470 & 0.690 \\
\hline 2 & 33 & 101 & Cyprus & 0.220 & 0.359 & 0.094 & 0.202 & 0.396 & 0.400 & 0.360 \\
\hline 2 & 34 & 45 & Cambodia & 0.230 & 0.150 & 0.211 & 0.116 & 0.097 & 0.061 & 0.210 \\
\hline 2 & 35 & 81 & Estonia & 0.260 & 0.492 & 0.506 & 0.473 & 0.499 & 0.486 & 0.510 \\
\hline 2 & 36 & 142 & Jordan & 0.290 & 0.049 & 0.593 & 0.498 & 0.066 & 0.055 & 0.590 \\
\hline 2 & 37 & 83 & Hungary & 0.300 & 0.185 & 0.152 & 0.033 & 0.524 & 0.309 & 0.190 \\
\hline 2 & 38 & 98 & Albania & 0.310 & 0.082 & 0.220 & 0.503 & 0.472 & 0.323 & 0.500 \\
\hline 2 & 39 & 43 & Australia & 0.330 & 0.147 & 0.093 & 0.298 & 0.821 & 0.487 & 0.300 \\
\hline 2 & 40 & 115 & Dominican Republic & 0.350 & 0.000 & 0.429 & 0.040 & 0.312 & 0.214 & 0.430 \\
\hline 2 & 41 & 94 & Norway & 0.390 & 0.098 & 0.059 & 0.073 & 0.205 & 0.271 & 0.100 \\
\hline 2 & 42 & 96 & Sweden & 0.410 & 0.189 & 0.060 & 0.226 & 0.234 & 0.473 & 0.230 \\
\hline 2 & 43 & 93 & Georgia & 0.470 & 0.404 & 0.492 & 0.582 & 0.654 & 0.205 & 0.580 \\
\hline 2 & 44 & 105 & Romania & 0.500 & 0.265 & 0.307 & 0.170 & 0.237 & 0.010 & 0.310 \\
\hline 2 & 45 & 153 & Morocco & 0.520 & 0.360 & 0.484 & 0.461 & 0.004 & 0.002 & 0.480 \\
\hline 2 & 46 & 155 & Tunisia & 0.530 & 0.033 & 0.039 & 0.018 & 0.010 & 0.010 & 0.040 \\
\hline 2 & 47 & 97 & Ukraine & 0.560 & 0.258 & 0.474 & 0.497 & 0.616 & 0.276 & 0.500 \\
\hline 2 & 48 & 100 & Bulgaria & 0.590 & 0.250 & 0.402 & 0.227 & 0.597 & 0.305 & 0.400 \\
\hline 2 & 49 & 109 & Belgium & 0.600 & 0.462 & 0.555 & 0.701 & 0.213 & 0.500 & 0.700 \\
\hline 2 & 50 & 80 & Czech Republic & 0.620 & 0.064 & 0.322 & 0.072 & 0.659 & 0.362 & 0.320 \\
\hline
\end{tabular}




\begin{tabular}{|c|c|c|c|c|c|c|c|c|c|c|}
\hline 2 & 51 & 51 & Korea South & 0.660 & 0.004 & 0.039 & 0.010 & 0.489 & 0.646 & 0.040 \\
\hline 2 & 52 & 107 & Portugal & 0.720 & 0.040 & 0.047 & 0.059 & 0.144 & 0.118 & 0.060 \\
\hline 2 & 53 & 89 & Switzerland & 0.770 & 0.418 & 0.531 & 0.650 & 0.608 & 0.322 & 0.650 \\
\hline 2 & 54 & 111 & Ireland & 0.780 & 0.157 & 0.121 & 0.089 & 0.155 & 0.150 & 0.160 \\
\hline 2 & 55 & 91 & Denmark & 0.900 & 0.128 & 0.082 & 0.089 & 0.233 & 0.287 & 0.130 \\
\hline 2 & 56 & 86 & Poland & 0.980 & 0.041 & 0.118 & 0.049 & 0.171 & 0.108 & 0.120 \\
\hline 2 & 57 & 139 & Bahrain & 0.980 & 0.460 & 0.502 & 0.658 & 0.553 & 0.474 & 0.660 \\
\hline 2 & 58 & 95 & Russia & 1.030 & 0.311 & 0.245 & 0.251 & 0.440 & 0.427 & 0.310 \\
\hline 2 & 59 & 79 & Croatia & 1.050 & 0.185 & 0.369 & 0.102 & 0.445 & 0.125 & 0.370 \\
\hline 2 & 60 & 60 & Singapore & 1.060 & 0.388 & 0.386 & 0.756 & 0.656 & 0.792 & 0.760 \\
\hline 2 & 61 & 112 & Netherlands & 1.090 & 0.077 & 0.105 & 0.327 & 0.722 & 0.563 & 0.330 \\
\hline 2 & 62 & 137 & Canada & 1.090 & 0.499 & 0.712 & 0.604 & 0.696 & 0.467 & 0.710 \\
\hline 2 & 63 & 123 & Mexico & 1.160 & 0.434 & 0.542 & 0.109 & 0.180 & 0.093 & 0.540 \\
\hline 2 & 64 & 146 & Saudi Arabia & 1.350 & 0.413 & 0.180 & 0.625 & 0.127 & 0.133 & 0.630 \\
\hline 2 & 65 & 63 & Thailand & 1.370 & 0.431 & 0.634 & 0.752 & 0.099 & 0.128 & 0.750 \\
\hline 2 & 66 & 102 & Greece & 1.950 & 0.050 & 0.158 & 0.130 & 0.153 & 0.217 & 0.160 \\
\hline 2 & 67 & 82 & Germany & 1.970 & 0.090 & 0.168 & 0.310 & 0.657 & 0.464 & 0.310 \\
\hline 2 & 68 & 55 & Malaysia & 2.220 & 0.564 & 0.588 & 0.735 & 0.666 & 0.550 & 0.740 \\
\hline 2 & 69 & 113 & United Kingdom & 2.230 & 0.184 & 0.121 & 0.152 & 0.694 & 0.447 & 0.180 \\
\hline 2 & 70 & 78 & Austria & 2.300 & 0.100 & 0.107 & 0.232 & 0.415 & 0.332 & 0.230 \\
\hline 2 & 71 & 138 & United States & 2.670 & 0.271 & 0.490 & 0.346 & 0.824 & 0.359 & 0.490 \\
\hline 2 & 72 & 77 & Turkey & 2.760 & 0.299 & 0.320 & 0.347 & 0.005 & 0.039 & 0.350 \\
\hline 2 & 73 & 106 & Italy & 3.780 & 0.040 & 0.115 & 0.472 & 0.303 & 0.289 & 0.470 \\
\hline 2 & 74 & 108 & Spain & 5.560 & 0.263 & 0.417 & 0.276 & 0.451 & 0.346 & 0.420 \\
\hline 2 & 75 & 110 & France & 7.120 & 0.251 & 0.103 & 0.242 & 0.403 & 0.519 & 0.250 \\
\hline \multicolumn{11}{|c|}{ Total $\mathrm{N}=152$} \\
\hline
\end{tabular}

Outlier countries:

\begin{tabular}{|c|c|c|c|c|c|c|c|c|c|c|}
\hline Casecode & Country & $\mathrm{CDI}$ & EFIA & LDI & RFA & $\begin{array}{c}\text { RFIPe } \\
\text { w }\end{array}$ & $\begin{array}{c}\text { DiffAr } \\
\text { riv } \\
2014\end{array}$ & $\begin{array}{c}\text { DiffAr } \\
\text { riv_20 } \\
15\end{array}$ & $\begin{array}{c}\text { DiffRe } \\
\text { c } \\
2014\end{array}$ & $\begin{array}{c}\text { DiffRe } \\
\text { c } \\
2015\end{array}$ \\
\hline 46 & China & .154 & .1538 & .536 & .6643 & .6435 & -13.71 & -13.76 & -5.31 & -5.47 \\
\hline 69 & India & .667 & .4182 & .914 & .3260 & .3460 & -16.47 & -17.00 & -1.04 & -1.10 \\
\hline 49 & Japan & .012 & .0119 & .035 & .5406 & .5416 & -.47 & .06 & -5.63 & -4.40 \\
\hline
\end{tabular}

